\title{
,new \\ COVID-19 Pandemic and Its Effects on the Usage of Information Technologies in the Construction Industry: The Case of Romania
}

\author{
Vlad Leontie $^{1, *(\mathbb{D})}$, Liviu-George Maha $^{2}(\mathbb{D})$ and Iuliana Claudia Stoian ${ }^{3} \mathbb{D}$ \\ 1 Doctoral School of Economics and Business Administration, Alexandru Ioan Cuza University, \\ 700057 Iași, Romania \\ 2 Department of Economics and International Relations, Faculty of Economics and Business Administration, \\ Alexandru Ioan Cuza University, 700505 Iași, Romania; mlg@uaic.ro \\ 3 Department of Management, Marketing and Business Administration, Faculty of Economics and Business \\ Administration, Alexandru Ioan Cuza University, 700505 Iași, Romania; iuliana.bobalca@uaic.ro \\ * Correspondence: vlad.leontie@student.uaic.ro
}

check for

updates

Citation: Leontie, V.; Maha, L.-G.;

Stoian, I.C. COVID-19 Pandemic and

Its Effects on the Usage of

Information Technologies in the

Construction Industry: The Case of

Romania. Buildings 2022, 12, 166.

https: / / doi.org/10.3390/

buildings12020166

Academic Editors: Ricardo

Codinhoto and Jurgita

Antucheviciene

Received: 7 December 2021

Accepted: 1 February 2022

Published: 3 February 2022

Publisher's Note: MDPI stays neutral with regard to jurisdictional claims in published maps and institutional affiliations.

Copyright: (C) 2022 by the authors. Licensee MDPI, Basel, Switzerland. This article is an open access article distributed under the terms and conditions of the Creative Commons Attribution (CC BY) license (https:// creativecommons.org/licenses/by/ $4.0 /)$.

\begin{abstract}
The COVID-19 pandemic has made the world face a whole new reality, and the measures taken for slowing the spread of the disease included social distancing, as well as national, regional, or local lockdowns and restrictions regarding the movement of people. For such an important sector of the Romanian economy as the construction industry, the restrictive measures imposed by the authorities led to postponing, delaying, or stopping the current projects. This paper aims at investigating the main effects of the COVID-19 pandemic on the Romanian construction sector, as well as the role of the digitalization process in mitigating the negative impact on the companies activating in this domain, in the context of the current levels of use of information technologies. The research involved the use of qualitative (exploratory in-depth interviews) and quantitative (online surveys applied to members of the local building sector, such as engineers, architects, contractors, and managers) data collection methods, respectively descriptive statistics for data categorization and interpretation. In general, the Romanian construction sector was only slightly affected, with the most significant negative effects being the delays and cost overrun due to safety and health issues. This paper is one of the first studies to explore and assess the effects of COVID-19 on the Romanian construction industry and the role of digitalization in reducing the pandemic impact. The main findings reveal that the companies in this industry that have a high digitalization degree overpassed in a smoother manner the current pandemic situation.
\end{abstract}

Keywords: COVID-19 pandemic; Romanian construction sector; information technologies; digitalization

\section{Introduction}

The construction industry holds a key role in the economy of the European Union (EU), being one of the sectors that can provide clear solutions when it comes to any social, energetic, or climatic changes. Representing approximately 9.5\% of the whole EU GDP [1], it is one of the industries with a vital economic role and serves as one of the main pillars of the European economy. The year 2019 was indeed one with positive outcomes for the whole EU construction sector, which recorded a substantial expansion in terms of investments, but it also marked the appearance of the new Coronavirus in Wuhan City in China [2].

The World Health Organization has classified the COVID-19 (related disease, which causes acute respiratory problems) as a pandemic in 2020 [3], and one of the main reasons for this was the fact that, besides its direct effects upon the health of the individuals, a very high infectious rate accompanied by a high spreading speed were registered. For stopping the illness, major measures have been adopted not only at a local level, but also at the global one: social distancing, restrictions for mass events, partial or total lockdown, etc. 
The actions taken for reducing the spreading of the virus exert a huge impact on the European economy, and the consequences of these measures have started to appear, many states facing either recession or decline in their economic activities. The Romanian and the European construction sectors do not make an exception when it comes to bearing these consequences, and a decline in the work volume of the industry, accompanied by a sinking of the level of investment, may be expected [4].

However, the high complexity level of the construction industry and the extremely long process of building created several difficulties when implementing the restrictive actions because measures that normally apply to other industries, such as working from home (home office) or social distancing, do not apply when it comes to on-site jobs. A carpenter or a plumber cannot work from home, and besides, casting a simple concrete wall requires at least 3-4 persons that need to come together and are not able to keep the $1.5 \mathrm{~m}$ distance rule. In addition, the fragmented structure of the industry, with over 3 million enterprises at EU level, of which over 95\% have less than 20 workers [1], made it particularly difficult to implement the different COVID-19 restrictive rules.

The internationalization of the European construction market allows companies to work within the European Union without too many obstacles, but because of the recent (partial) lockdown, many companies have been affected in either a direct or indirect way (material workflow). The quarantine regulations led to delays in the construction process, and the human capital workflow suffered dramatically in the case of international projects.

The Romanian construction industry is one of the most important actors in the Romanian economy, representing $12.6 \%$ of Romania's GDP [5]. Implying over 482,000 workers directly, activating in more than 55,000 companies [1], this sector has suffered for many years because of the lack of human capital induced by migration [6] and of the lack of digitalization (according to the European Commission's Digital Economy and Society Index, Romania is ranked 26th out of 28 member states) [5]. The measures imposed for stopping the spreading of the COVID-19 pandemic had certain effects on the Romanian construction sector, and up to this point, a relevant study to assess the impact of pandemic has not yet been conducted.

The aim of this paper is to investigate the main effects of the COVID-19 pandemic on the Romanian construction sector, as well as the role of the digitalization process in mitigating the negative impact on the companies activating in this domain, in the context of the current level of use of the information technologies. To achieve this aim, some specific objectives were formulated: (1) identifying the main effects of the COVID-19 pandemic on the Romanian construction sector; (2) identifying the most important countermeasures taken by the Romanian companies; (3) analyzing the level of knowledge and the use of information technologies in the building sector in the pandemic context; (4) evaluating the impact of the COVID-19 pandemic on the Romanian construction sector; (5) analyzing the efficiency of the countermeasures taken by the Romanian building companies, special attention being paid to those involving the use of information technologies.

\section{Literature Review}

Regarding the COVID-19 pandemic and its impact on the construction industry, the existing literature offers references for a multitude of effects identified all over the world. Among the most common consequences, the slowing down of the processes, leading to disruption and delays [7-11], stoppage of the construction projects [7], suspension of the current projects, involving time, and cost overrun [8], can be counted. For instance, Zamani et al. [8] collected 20 interviews from different owners or project managers within the Malaysian construction sector, and the problems the industry encountered when dealing with the pandemic were grouped in six different categories: project timeline, reduced labor, logistics, late payment, increased project costs, and reduced number of projects. The study highlights the decline in the number of projects (affecting 60\% of the analyzed population) and the fact that the companies are struggling to obtain new works because of the increased competitiveness and to the little award of new tenders from the local authorities. Despite the 
fact that the government of Malaysia offered financial aid in the form of grants (PRIHATIN Special Grant MYR3000) or funding programs (PENJANA Micro Finance) for helping the companies in this pandemic crisis, some contractors' critics were found to be regarding either the eligibility criteria existing or the low amount of funds.

At the same time, Gamil and Allhagar [11] offer a complex perspective regarding the impact of the COVID-19 pandemic on the construction industry. Based on 10 interviews and 129 questionnaires, they suggest that the delays of the current projects, caused by anti-COVID-19 spreading regulations and lockdowns, produced deep effects among the industry. In addition, another main effect of the current pandemic on the building sector is the cost overrun of the actual construction projects. This comprehensive work also reports a neutral position of the sector regarding the survival of the industry, despite a high financial impact of the crisis.

The study of King et al. [12] also provides valuable information regarding the effects of COVID-19 on the building sector. After receiving 127 survey responses from the architectural, engineering, and construction organizations, the authors were able to identify many effects, such as reduced foreign investment in the industry, lower demand of constructionrelated projects, disruption in the construction supply chain, or lower productivity. The same authors investigated the effects of the pandemic on infrastructure projects [13] using 20 phone interviews and grouping the consequences of COVID-19 in two main categories: financial and productivity. Among the main effects, the cost overrun of the projects due to the implementation of the safety operating procedures, problems and delays in the supply chain mechanism, or labor shortages may be counted. The cost overrun exists, but an exact approximation of the extra costs generated by COVID-19 is hard to be conducted, with the delays occurring in many directions in terms of material supply or generated from labor shortages.

Other relevant works are those of Agyekum et al. [14], who analyzed the impact of the pandemic on the construction industry in Ghana. After collecting nine interviews with key professionals of the industry and performing a thematic analysis, authors concluded that, among the major effects of COVID-19, the decrease in work rate, increased material costs arising from border closure, and delays have been spotted. An important aspect, which should be emphasized when considering the COVID-19 impact on the construction industry, is the company size and the type of the country where it is located in terms of development stage (developing/developed) [15]. Many researchers noticed that the smaller construction firms were severely affected by the current pandemic [16], mostly in developing countries [15].

Regarding the countermeasures that address the COVID-19 impact, it was observed that during the current pandemic, the companies around the world adopted different strategies and different measures when being confronted with this crisis. Educating the working force on the virus [8,14], effective checks on entry and exit from construction sites [9], and financial aids [8] from government or other public authorities represent some of the countermeasures encountered worldwide along the construction sector. Among the most efficient strategies in overcoming the pandemics, the switching to online work [7] by using virtual working, the reduction of the on-site works (where possible), and the travel ban were identified [17]. Moreover, as Ogunnusi [7] mentions, the whole situation acted as an "opportunity to improve the virtual alternatives" and the switching from onsite to online environment was accelerated. At the same time, the implementation of different risk management systems or frameworks could help practitioners in fighting the virus and its negative impact [15].

The study of Salami et al. [18] is an important asset when observing the countermeasures that address COVID-19 effects. After having six brainstorming sessions with construction professionals, a set of questionnaires was sent to practitioners from the industry, with 103 responses being received. After processing the results, the following measures were identified as possible minimizers of the business disruption: restricted site access, social distancing and restriction of physical interactions, increased hygiene, contact risk 
identification, self-isolation, and heightened construction site safety. These measures were rated as being very effective, and the adoption of social distancing or increased hygiene reached high values among the industry [18].

The digitalization of the construction sector is directly related to the use of the different information technologies or the so-called Construction 4.0 technologies existing in the sector. In recent years, the use of such technologies has intensified, and due to their huge potential in increasing productivity, making the management of the processes more efficient and improving the necessary time for different activities, they started to gain notoriety $[19,20]$. Unlike other sectors for the construction industry, such as manufacturing, there is no single integrated solution that brings together all the Construction 4.0 technologies; therefore, it is very important to select the technologies that could bring most improvements to the industry [19]. During the literature analysis, the following renowned technologies have been found: BIM, 3D modeling, Internet of Things (IoT), augmented reality, 3D printing, and drones $[19,20]$. In addition, particular attention is given within the industry to data science, concerning data transfer, connectivity, cloud, and cloud computing, due to the latest challenges when dealing with construction projects with huge data volumes [19].

In mitigating the negative impact of COVID-19 upon the construction sector, digitalization plays a central role. The construction industry is still strongly anchored in the existing traditional processes and methods [19]; therefore, the latest Construction 4.0 technologies offer a viable solution for a better overpassing of the current crisis. Several digital sectors such as digital fabrication, prefabrication, and monitoring could lead to different advantages when it comes to COVID-19 and its stoppage measures (social distancing, safety, and hygiene on the construction sites) [19]. Moreover, tools based on " $n$ " dimensions such as modeling and BIM allow working from home, thus reducing the extra costs that pop up from obeying the safety regulations (masks, disinfectants, safety shields, or similar). A relevant work in terms of digitalization is the one of Ogunussi [7], which underlines among the "positive" effects of the pandemic the forced steps made towards digitalization by the compulsory usage of technologies and the deployment of the different technological tools, respectively, by the enhancement of their usage.

There have been several works related to the COVID-19 effects in Romania, such as the study of Radulescu et al. [21], which offers a complex perspective of the pandemic effects on the Romanian labor market. They identify the most important challenges that the workforce had to deal with, and the changes that took place in this market. At the same time, other papers, such as the one of Dascalu [22], identify items (such as the response of the Romanian healthcare system or the importance of the social-cultural factors) when dealing with the actual pandemic. The main challenges that Romania faces and major areas for improvement were outlined.

Many studies are focused on studying the effects of COVID-19 on the construction industry or studying the countermeasures that address the pandemic either in a general matter (worldwide) [7] or in a particular matter (country specific) [8], but none of the studies focus on the Romanian construction industry. Moreover, there is much valuable research regarding Romania related to COVID-19, but there is little or no work that analyzes the construction sector in particular. In addition, up to this point, there is no paper that deals with the usage of the informational technologies under the pandemic circumstances in the Romanian building sector.

After analyzing the existing literature, a multitude of studies were found relevant as a baseline of knowledge in terms of COVID-19 main effects on the construction sector, countermeasures applied in the industry and their implementation, usage of the information technologies in the pandemic context, and digitalization. The delays that occur inside the building industry due to the anti-COVID-19 spreading regulations and to the lockdown measures have been reported by many researchers $[7,11,13]$ as having a high impact on the sector. Their effects are propagated in many directions, such as material supply, planning, or labor shortages. The investment level, at least in the public sector, reached lower values compared to the previous years, and this is definitely leading to an increased competition 
between the companies, pushing the small and medium enterprises to compete with the big companies for obtaining projects [8]. Governments around the world provide different alternatives for the construction companies to overcome these difficult times, such as different funding opportunities, grants, or fiscal facilities $[7,8]$. Despite the positive reaction of the public sector, not all the measures taken are efficient, as Ogununussi [7] reported. COVID-19 heavily affected the industry in terms of cost overruns, and a multitude of construction projects must suffer from this effect $[8,11,13]$. An exact approximation of the extra costs caused by the pandemics is hard to be obtained [13].

Through the main countermeasures existing, home office, social distancing, safety measures and regulations, or increased hygiene can be counted. The social distancing and the increased hygiene inside the industry embrace a high adoption, also reaching good values in terms of efficiency [18].

Digitalization is becoming more and more present in the construction industry worldwide and offers a diverse range of solutions in terms of existing information technologies, such as BIM, 3D modeling, Internet of Things, drones, or data science [19,20]. These innovative solutions could offer meaningful help in terms of mitigating the negative impact created because of COVID-19 by offering advantages such as digital fabrication, prefabrication, or monitoring. In this way, remote work (home office) and social distancing can be achieved, as well as avoiding cost overruns due to increased safety regulations or increased hygiene [19].

\section{Materials and Methods}

\subsection{Research Design}

The scope of this work is to obtain a solid response from the Romanian construction industry regarding the main effects that COVID-19 has on this branch and the usage of information technologies during the pandemic phase in mitigating the negative impact on the companies activating in this domain; in this context, a mix research methodology was used. For data collection and data analysis, the study combined qualitative and quantitative methods. The research design is structured and presented in Figure 1.

As Figure 1 indicates, the first step of the research was the literature review, followed by the qualitative study, which is six in-depth interviews being conducted with experts from the industry. The purpose of the qualitative phase was to obtain a competent and detailed approach, which can be used to better investigate the research context, which was to understand experts' opinions regarding the effects of COVID-19 on their companies and on the entire construction sector, the implemented measures, and the role of digitalization in mitigating the negative impact on the companies activating in this domain. In addition, the participants' answers were very useful in order to collect items for the questionnaire that was applied for the quantitative survey.

The third step of the research, the quantitative survey, was found appropriate for obtaining views from a large number of individuals. In this matter, an online questionnaire survey was prepared and sent to different actors of the Romanian construction sector: construction companies, contractors, engineers, quantity surveyors, independent laboratories, architects, and contractors. Regarding the data collection method, the authors considered that the electronic questionnaire was the best option, due to the present COVID-19 pandemic situation and to the reduced time for collecting the data. The costs of performing such a task are low, and through the benefits, one can count on that the target population to which these surveys are sent can reach a solid number [23].

The purpose of the research was to measure the magnitude of the effects upon the construction industry, which came along with the measures to stop the COVID-19 disease. The fact that the format was predetermined in response categories underlines the quantitative character of the research. The numerical aggregation of the results together with the statistical description were also used in analyzing the responses obtained, with the quantitative aspect of the research being once again noticed. 


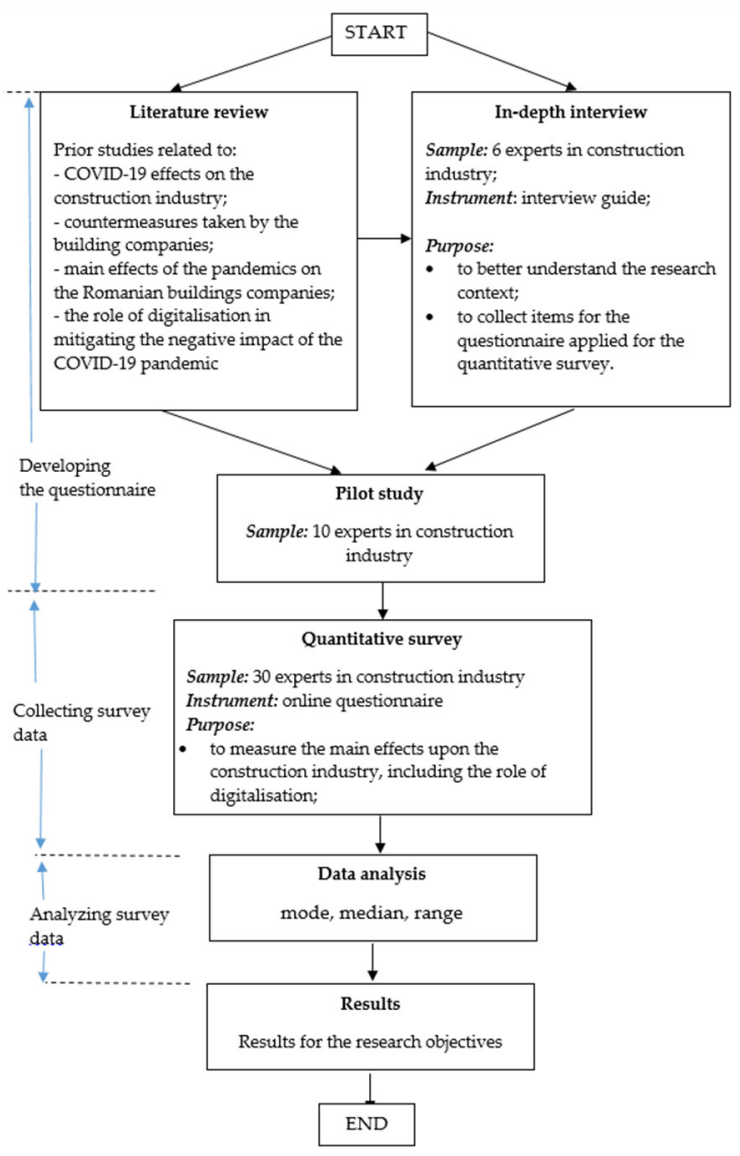

Figure 1. Research design.

\subsection{Population and Sampling Techniques}

A quite common definition of the population is given by Rahi, S. [24], and it is namely all people, entities, or items that one tries to understand. In the case of the current study, the target population shares the feature of working inside the construction industry in the Romanian construction market, and it consists of all the parties having an active role in the construction process, from material producers to general contractors, architects, specialists, and testing institutes.

The construction industry of Romania contains more than 55,000 companies and has more than 482,000 active workers [1]; therefore, a very structured character of the population can be noticed. Testing the whole construction industry would not be possible, due to the high data set trying to be reached, to reachability issues, and to time constraints.

For the qualitative approach, in performing the interviews, the sampling technique used was convenience sampling. The authors have chosen from their circle of acquaintances six renowned experts with experience and a rich background of activities performed in the construction field. In the cases where qualitative research is followed by quantitative research, usually the sample size would be small $[25,26]$. Due to the pandemic context and the fact that in business studies respondents are less likely to attend time consuming research, we managed to discuss with six representatives from the construction management sector [27].

When choosing the experts, the following criteria were looked for: specific academic background in the construction field, work experience of at least 10 years, active member of the construction industry in the least 10 years, scientific publications in the field, and to have managerial positions inside their organization [28]. Table 1 presents the main characteristics of the interview participants. All six experts participating in the qualitative interviews are engineers who have worked inside the construction industry for the last 
10 years and have a decision role in the company. For instance, one expert has the role of manager inside a design, expertise, and consulting company, who at the same time offers services as building inspector and supervisor. Another specialist invited to the interview is a manager and technical director at his own small company (three employees) activating in the design area and doing mostly structural design for private or public entities. In addition, regarding their education, four of the experts have master's degrees and two participants possess the PhD title.

Table 1. Profile of interviewees.

\begin{tabular}{ccc}
\hline Field of Activity & Role of Interviewee & Experience in Construction \\
\hline Residential construction & Manager & 10 \\
Civil Engineering & Civil engineer & 11 \\
Non-residential and residential & Leading engineer & 10 \\
construction & Manager & 15 \\
Residential construction & Manager & 12 \\
Active in all existing fields & Manager and technical director & 10 \\
Active in all existing fields & Mand \\
\hline
\end{tabular}

For the quantitative survey, a reasonable number of questionnaire responses would be necessary to ensure the quality of the research. A number of 130 online surveys were sent to the industry decision makers, and a total number of 30 responses was obtained. Obtaining the public data of the companies was realized using different search engines such as Google or Bing. The sample was not defined but obtained.

Sample size is a research limitation since it is small, resulting in weak evidence. It is not surprising that there is a reduced sample size, both due to the stressful nature of the pandemic (a challenging time) and to the characteristics of respondents (businesspeople) [29]. As above-mentioned, the studies of Hill, Chassan, and Roscoe were found relevant when selecting the required responses [25,26,30]. The Romanian construction sector "lacks" time, and usually response percentages when sending online questionnaires are very low. On the other hand, there are research studies in the construction sector with samples of 30 participants [31,32]. Moreover, a response rate of $23 \%$, while considered low in consumer research, is acceptable in business research where the companies are more reluctant to respond due to the lack of time [33]. The obtained response rate renders the use of complex and sophisticated statistical analysis methods unnecessary, so only a statistical description of the data set and a numerical aggregation of the data is required.

The main sampling techniques used in performing this study are probability sampling and non-probability sampling. Probability sampling is an approach that gives each unit an equal chance to be selected [24]. The simple random sampling was used, appealing to search engines such as Google or Bing in tracking construction companies that are active in the Romanian industry. By obtaining the public data as contact details and using e-mail services, an online questionnaire was sent to 130 firms. The online survey was designed using Microsoft Forms, an application that sends an immediate answer when the person performing the survey clicks the submit button.

The concept of non-probability sampling refers to a sampling procedure in which the probability that any of the selected units will be selected cannot be tested or verified [24]. From the multitude of non-probability sampling methods, the researcher has chosen convenience sampling along with "snowball" sampling as appropriate techniques. The above-mentioned techniques have been because of a relatively fast data gathering possibility and to the accessibility of the subject. In the case of the online surveys, the questionnaire was sent to the population that was "at hand" to the researcher: work colleagues, former classmates, and former working colleagues. The author asked his convenience sampling population to pass the survey to other work colleagues that are active in the Romanian construction market; therefore, the presence of snowball sampling could also be noticed in the performed research. 


\subsection{Interview Design and Framework}

The qualitative method of data collecting that was chosen is the exploratory in-depth interview with a sample of six experts from the construction industry. The interviews took place before the survey, during a week, with each interview lasting for about $30 \mathrm{~min}$. The interviewer tried to understand the economic, political, and cultural context in which the expert was located. The expected outcome was not predefined, and the results give a useful view from someone who is "inside the boat". The interviews were performed using Skype so that the environment where it took place (online) was comfortable for the interviewed person, without stress factors and constraints of any kind. Besides, this specific mean was chosen because of movement restriction regulations and for respecting the pandemic rules. Due to the familiar environment where the interview took place, a high quality of the answers obtained can be confirmed.

Regarding the interview guide, most of the questions were open-ended, beginning with general (such as: "How did the construction market looked like before the pandemics started?") to more specific questions (such as: "How many projects did you have as the pandemic started?", "What happened with these projects during the pandemic time?", "Which strategies were developed for avoiding the pandemic related problems?", and "What is the role of digitalization, in your company, in the pandemic context?").

The questions prepared are clear and try to contain a single idea so that the expert will not be disturbed or confused when answering. Another characteristic of them is the ideal and interpretative specific function they have. No provocative or multiple questions were used to avoid misunderstanding and to maintain a positive flux of the interview. A preliminary literature review was realized before preparing the general questions so that an insight of the possible effects of the COVID-19 pandemic can be obtained [11,15,31,34,35].

The main themes of in-depth interviews were the effects of the COVID-19 pandemic crisis on the Romanian construction sector, the measures that were taken in this context, and the role of digitalization during the crisis. The participants shared their insights and experiences regarding the current pandemic state, and they stated their opinions freely, without any constraints. The interviewed persons also made conclusions regarding the effects of the current pandemic on short and long terms and gave a useful insight of the digitalization level of the industry. They also both formulated quality conclusions with respect to the measures that can be taken to smoothly avoid similar events in the future. The interview language is Romanian, and the whole procedure was recorded and transcribed for a better analysis.

A brief thematic analysis was chosen as the proper method of data analysis. It contained transcribing, manual coding (spotting the effects of COVID-19 on the construction industry), and the generation and review of the common themes (effects can be grouped in categories).

\subsection{Questionnaire Design and Data Analysis}

The questionnaire was performed using Microsoft Forms, a useful tool that offers real time responses after answering all obligatory questions and after submitting the responses. It is to be noted that no incomplete online survey questionnaires can be created due to the establishment of the obligatory fields for the crucial questions. In order to ensure that the survey is valid and reliable, we conducted a previous pilot study on a sample of 10 experts in the construction sector upon the final questionnaire was built. All Romanian construction sector professionals involved in the pilot study have a working experience of more than 12 years in the field (two of them have worked for more than 30 years in the construction sector) and are still active in the building industry. Moreover, three of the participants are members of the teaching staff of the specialized faculty within the technical university of Iasi. After answering all the questions included in the questionnaire, they provided proper feedback and suggested, clarified, or added different aspects related to the questionnaire concerning its structure, the construction validity, the necessary time for responding, clarity of the formulation, and grammar. 
The online survey was divided into four relevant parts, namely general information, effects of the COVID-19 disease on your organization, adoption and efficiency of the recommended anti-COVID-19 measures, and digitalization/use of information technologies. The first part offered information regarding the age, gender, level of education, work experience [31], industry sub-sector where the respondent is active, job type, and details regarding the size of the organization [36].

The second part tried to identify and rate the COVID-19 effects on the organization of the respondent. The evaluation of the effects was realized using a Likert scale with the following interpretation: 1-not affected, 2-less affected, 3-neutral, 4-considerably affected, and 5-extremely affected. This step was performed so that in a later data analysis point relevant conclusions can be drawn using statistical indicators such as median value and standard range. These statistical indicators offer us valuable information regarding the data sets and how they are spread across the population.

In the third part, regarding the adoption and the efficiency of the measures adopted in order to stop the Corona epidemic, the same Likert scale as above was used. It was investigated to observe in which proportion the measures had been adopted, and afterwards, their efficiency was tested.

The last part of the questionnaire addresses the topic of digitalization and technology information, as well as its use in mitigating the negative impact of the COVID-19 pandemic. Therefore, five questions were formulated to discover the level of digitalization of the Romanian's construction industry [37] (respectively, the role it plays in overcoming this novel event) and the current level of knowledge and usage regarding the existing information technologies.

The extent to which the Romanian construction sector uses the existing digital tools was determined using a 5-Point Likert scale. The Likert scale measures people's opinions and perceptions, and it was chosen because it has the advantages that are simple to construct, easy to read and complete for the participants (does not create misunderstandings), and it produces a highly reliable scale. The 5-point Likert scale is considered one of the most appropriate because it is likely to provide accurate results [38] and being, at the same time, not tenable [39]. The 4-point Likert scale is usually desirable when investigating groups with low motivation, such as young respondents or individuals with a lower capacity of understanding [38]. Therefore, the 5-point Likert is considered the best option. In addition, the character of the data is ordinal; therefore, means such as standard deviation and mean shall not be used, but measurement tools such as mode, range, and median are used.

The questionnaire was designed using the results of the literature review and of qualitative research. The items measuring the effects of the pandemic on the construction sector, the measures implemented, and the use of digital resources were built based on the answers of the six experts in the interviews. For example, when analyzing the results of the qualitative research (Section 3.2), a list of effects was generated and introduced in the questionnaire such as: projects stopped, projects delayed, projects cancelled (items 1,2, and 3), cost overrun due to anti COVID-19 spread regulations taken by authorities, and having effects of COVID-19 led to a boosting of the construction market. Moreover, these effects were found in many references [7-13], and the fact is emphasized in the section containing the literature review.

As for measures adoption, the questionnaire contained items from the in-depth interviews, such as social distancing in offices, construction sites, and home offices or placing disinfectants, gloves, and masks in the common spaces. In addition, the role of digitalization in the construction sector was discussed during the interviews, focusing on the pandemic effects and items that were built for the questionnaire including digital access for project stakeholders using online-organized platforms and process automation: time management systems, production, and time optimization.

The research questions have fixed answers, and one can notice a linearity concerning the hierarchy of phases; the results can be generalized, compared, and summarized. The period used for collecting the responses was four weeks, between 5 February and 5 March 2021. 


\section{Results}

Thirty responses were received for the online survey questionnaires. The participants were both male and female, the age was not included in all the categories, and all of the survey respondents possess at least a bachelor qualification in the domain. This suggests that the target population has a solid academic background.

From the questions addressed, two of them had a multiple-choice answer, namely role or position held (this item refers to the category where the respondent's job would best suit) and activity sector (in which one of the construction industry sub-sectors operates). It is important to notice that at this point, one may suit more than two categories; a proper example in this matter being a general contractor, who can simultaneously play the role of construction team. It is often the case in this industry that the general contractor performs the building shell, and the rest of the work is given to subcontractor companies.

The second question with multiple answer possibilities referred to the activity sector where the respondent is active. Here, the employer company of the respondent may offer both residential constructions as well as non-residential buildings. The purpose of this question is to determine the sector most likely to be affected by the current COVID-19 pandemic.

\subsection{Respondent's Profile}

From the respondents, a total of 20 agreed to provide details regarding either their name or their employer entity. It represents about $66 \%$ of the analyzed population, the level being relevant in exploring the consistency of the data.

Based on the answers obtained (Table 2), a profile of the respondent may be created. As it can be seen in this table, the educational background ranged between graduate and $\mathrm{PhD}$, with no entries being registered for postdoctoral education or underneath the graduate status. In addition, most of the subjects (40\%) have relevant experience in the domain: between 5 and 10 years, followed by professionals having between 10 and 15 years (about $33 \%$ ). This fact underlines highly qualified persons with a solid background in the domain that are capable of providing high quality answers to the actual effects of the COVID-19 pandemic on the construction industry.

Figure 2 presents the job profile of the respondents. At this point, the following job descriptions must be clarified: design area-architects, civil engineers, building service engineers, fireproof, or acoustic engineers, who are active in the design process, represent it. The construction team is the part represented by the teams who physically carry out the works at the construction sites. Companies that produce prefabricated elements and steel elements or similar suppliers for the industry represent members of the supply chain. Independent testing laboratories or topographical measurements represent the auxiliary entities. Consulting services for the owner regularly refer to management firms, site masters, and different technical experts.

As it can be noticed from Figure 2, the jobs in the design area represent $34.15 \%$ of the whole population. Respondents that have an active role inside the construction teams represent $24.39 \%$, while the general contractor holds a share of $19 \%$. The consulting services for owners make out almost $10 \%$ of the population who responded to the online survey. The auxiliary entities, the subcontractors, and other categories represent together less than $12.3 \%$. The actual online survey focused, as above-mentioned, on design area personnel and construction teams, which constitute about $60 \%$ of the entries registered.

According to Figure 3, most of the participants (33.33\%) have their activity sphere in the non-residential construction area. This consists of industrial buildings and facilities, office buildings, schools, hospitals, or similar buildings. The second activity sector (28.57\%) is represented by residential constructions, followed afterwards, with the same number of entries (12), by the rehabilitation and maintenance sector, and civil engineering works. 
Table 2. Respondents' profiles.

\begin{tabular}{|c|c|c|c|}
\hline Category & Options & Frequency & $\begin{array}{l}\text { Percent of Total } \\
\text { Population }(\%)\end{array}$ \\
\hline \multirow{3}{*}{ Education level } & Bachelor/Graduate & 8 & 26.67 \\
\hline & Master & 20 & 66.67 \\
\hline & PhD & 2 & 6.67 \\
\hline \multirow{5}{*}{ Work experience } & $1-3$ years & 3 & 10.00 \\
\hline & $3-5$ years & 1 & 3.33 \\
\hline & 5-10 years & 12 & 40.00 \\
\hline & $10-15$ years & 10 & 33.33 \\
\hline & $>15$ years & 4 & 13.33 \\
\hline \multirow{7}{*}{$\begin{array}{c}\text { Role } \\
\text { (Multiple choice) }\end{array}$} & Design area & 14 & 34.15 \\
\hline & General contractor & 8 & 19.51 \\
\hline & Subcontractor & 2 & 4.88 \\
\hline & Construction team & 10 & 24.39 \\
\hline & Auxiliary entities & 1 & 2.44 \\
\hline & Consulting services for owner & 4 & 9.76 \\
\hline & Other categories & 2 & 4.88 \\
\hline \multirow{6}{*}{ Organization size } & $<10$ & 7 & 23.33 \\
\hline & $10-50$ & 9 & 30.00 \\
\hline & $50-100$ & 8 & 26.67 \\
\hline & $100-250$ & 2 & 6.67 \\
\hline & $250-500$ & 2 & 6.67 \\
\hline & $>500$ & 2 & 6.67 \\
\hline \multirow{3}{*}{ Job type } & Office & 11 & 36.67 \\
\hline & Field & 3 & 10.00 \\
\hline & Mixed & 16 & 53.33 \\
\hline \multirow{4}{*}{$\begin{array}{l}\text { Industry sector } \\
\text { where active } \\
\text { (Multiple choice) }\end{array}$} & Residential construction & 18 & 28.57 \\
\hline & $\begin{array}{l}\text { Rehabilitation and maintenance } \\
\text { of the residential constructions }\end{array}$ & 12 & 19.05 \\
\hline & $\begin{array}{l}\text { Civil engineering (highways, bridges, } \\
\text { tunnels, special structures) }\end{array}$ & 12 & 19.05 \\
\hline & $\begin{array}{c}\text { Non-residential (office buildings, } \\
\text { schools, hospitals, } \\
\text { industrial constructions) }\end{array}$ & 21 & 33.33 \\
\hline
\end{tabular}

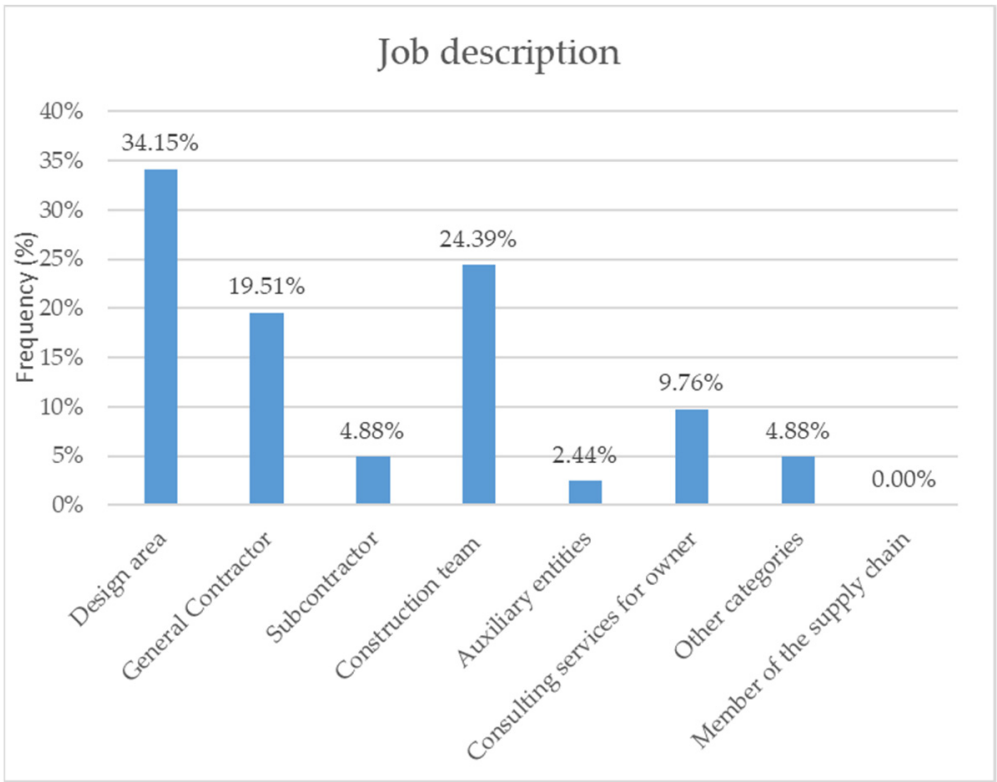

Figure 2. Job profile of the respondents. 


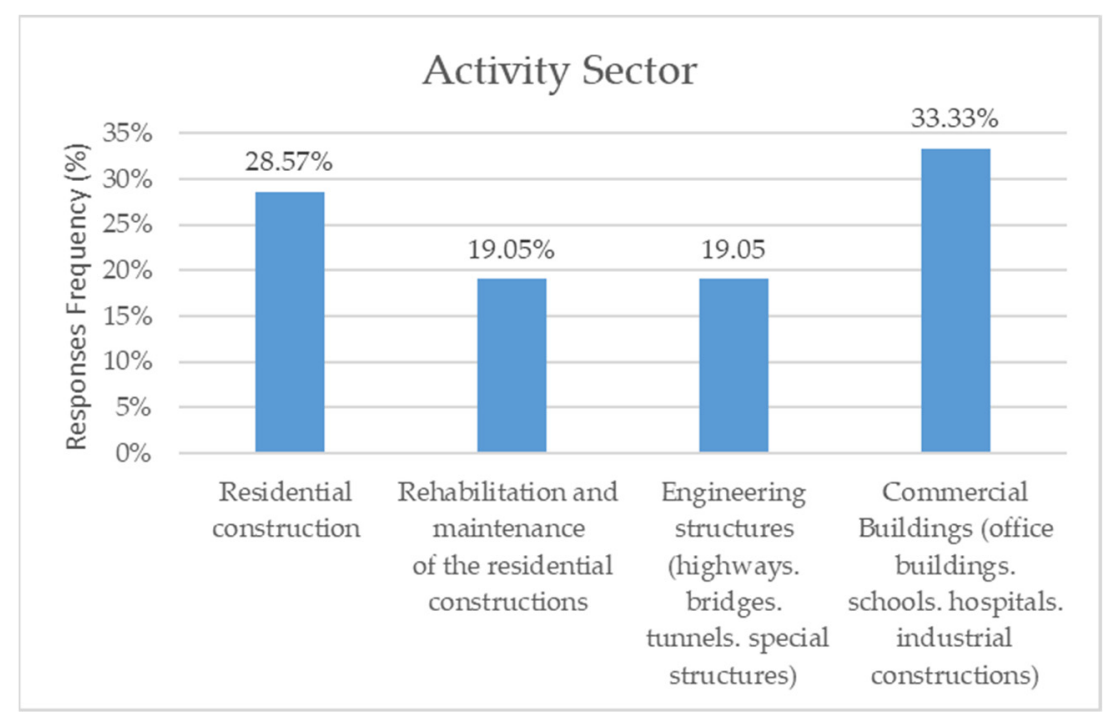

Figure 3. Activity sector of the respondents.

The organization size plays an important role and is often relevant for the volume of works that a company may simultaneously enterprise. The answers to the online survey revealed that $30 \%$ of the respondents carry out their jobs in entities that have between 10 and 50 employees. Eight entries (26.67\%) were recorded for companies that have between 50 and 100 workers, while micro companies represent $23.33 \%$ of the total sample. A percentage of $6.67 \%$ represents the medium large and very large companies (100 to 250, 250 to 500, and over 500 employees). It can be noticed that the core population consists of rather small and medium-small enterprises (between 1 and 100 employees), and the greater organizations (with more than 100 workers) constitute about $20 \%$ of the analyzed sample. The answers to this question confirm the industry structure existing at the European level; namely, that it mostly consisted of small and medium enterprises [1].

The respondent's type of job consists mostly of mixed jobs (53.33\%), followed by exclusively office jobs (36.67\%), and in the field jobs (10\%). Because the majority of the jobs have a mixed character, an increased difficulty degree in implementing the anti-COVID-19 regulations may be noticed.

\subsection{Interview Outcomes}

The exploratory in-depth interviews were conducted online due to movement restrictions and to social distancing. The environment was a familiar one for the interviewed experts. The six interviews maintain a semi-structured character with open and close-ended questions. The design of the interview allowed lengthy and detailed responses in most of the cases.

After transcribing and performing a short thematic analysis (coding, analyzing, summarizing, and grouping the results), the following main findings have been extracted. We grouped the results in five themes:

1. The construction market before the pandemic due to COVID-19

All the respondents agreed that, before starting the current COVID-19 pandemic, the construction industry had a very solid image, with an increasing level of investments. For instance, one expert talked about the "increasing trend in all areas related to the construction industry". In addition, another idea was that all sub-sectors (residential, civil, and non-residential) performed very well with an increased volume of work.

2. The effects of the pandemic crisis on the construction industry

As the pandemic started, the main challenges that this industry had to face can be summarized as follows: 
- Management of the online work. When asked about the biggest challenges that the sector and the expert had to deal with, the switching of the whole process from faceto-face to working from home was firstly reported. All respondents identified the fact that, at the beginning of the pandemic, the employees could not meet face-to-face. In addition, two of the experts described the process of transition from physical to online work as a transformation process in their behavior: "We were forced to find the best way to transform our activity in the online environment"; "Everything was designed before for working at the office or on different construction sites, we went through a process of transformation".

The correlation of the tasks and finding the best formula to make home office work were in the first step a bit difficult, but the profile of the company allowed turning into online activities smoothly: "We did online meetings, first it was difficult, but we managed the situation, we work in a design company".

- Separating the employees for social distancing and their temporary unavailability. Three participants describe this as an important challenge generated by the quarantine measures or due to proper illness. This problem "generated discomfort in solving tasks", as an expert told us.

- The demand in the first half of 2020 reached very low levels. For four of the respondents, the pandemic had a negative effect on the financial resources but, in time, the situation improved: "It was a state of numbness at first, then we found ways to carry out the activity".

Due to the pandemic context, changes were identified in the dynamic of the projects and time management related to those projects. For example, when the COVID-19 pandemic started in March 2020, one of the experts participating in the interview had three large ongoing projects. All three were stopped for about five weeks, and they suffered delays. Due to the lockdown conditions (March-May 2020), the access on different construction sites was not granted, and therefore, a temporary stop was the only possible option. Most of the projects were delayed, but there were no projects canceled.

- Increasing costs. In this category, we identified two topics: costs related to the projects and costs related to the compliance with hygiene and safety conditions.

The measures for stopping the spreading of COVID-19 led to "increasing the costs of the current projects of about 15-20\%", as one of the experts mentioned. In respecting the social distancing regulations, the need for more accommodations, the traveling conditions (a limited number of persons in a car), and the necessary equipment resulted in additional costs. Besides, the digital infrastructure contributed to increased costs.

Besides these challenges, a positive effect was identified by analyzing the answers of two experts; most of the institutions developed online systems for managing online documents, and the construction companies' employees did not waste time or effort to go in person to submit documents.

3. The measures for avoiding the pandemic problems

When analyzing the results, we observed that the measures were implemented according to the particularities of the sub-sector of the construction field. When looking at the construction teams that worked on the construction site, a rather reduced degree of interest concerning implementing strategies for avoiding COVID-19-related problems can be reported. The nature of the industry is, to a very high percent, an "on site" one, being dependent on technological processes and requiring presence and constant work (cannot be switched to online).

Among the strategies most implemented in the industry, the experts noted home office/online work. Other identified strategies that the companies adopted for avoiding the pandemic problems were relocations of the company personnel and maintaining just the minimum necessary employees in the offices.

For the small companies (represented by two experts), the implementation of COVID19 stopping measures (masks, gloves, disinfectant, and transport) did not lead to significant 
cost increases: "We are a small company, we didn't spend too much money for masks or disinfectant".

All of the participants considered that the efficiency of the measures was definitely high.

4. The digitalization strategy

All six respondents agreed that the digitalization of the construction industry was one of the most positive factors towards a better manner to avoid possible COVID-19-related problems: "digitalization is a positive factor, we work on our computers from home; it was a great opportunity in this period of time". Half of the respondents characterized digitalization as a major bridge for smoothly overcoming the pandemic, but unfortunately, the Romanian construction sector is mostly concentrated around the construction sites (field work). This type of work cannot be so easily digitalized, and they require human interactions and technological steps that cannot suffer from any interruption. The digitalization of the Romanian construction sector reaches a significant level, but it lags behind if compared to other major industries (IT, automotive, or similar).

Towards the "benefits" of this pandemic, two experts related that one of the huge steps that the Romanian industry performed is in the direction of digitalization of the public structure entities (building permits, placement certificates, and similar). Many institutions started to allow and the development of online application systems for obtaining building permits or different certificates.

5. General perspectives on the Romanian construction sector

Most of the participants appreciate that, in general terms, the Romanian construction sector is looking quite strong and is affected in a limited manner by the COVID-19 restrictions and disease. The response from the Romanian government and state was prompt and offered the industry many services for overcoming the pandemic, including tax reduction, technical unemployment, and other facilities. The long side effects will definitely appear in a couple of years due to the high inertia that this industry has (at this point, there are construction works being realized for projects that have been prepared years before): "In the next two years we will realize the impact of the pandemic on the construction sector".

The investments reached a lower rate when compared to the beginning of 2020, and the programmed number of investments decreased due to the uncertainty level generated by the pandemic. The fact that the developers would rather wait than invest underlines that the design area and the consulting services of the construction industry have quite a difficult time at this current point. According to the responses of three experts, "the worst has passed" (if the pandemic remains under the actual boundaries, there will be no other lockdowns or similar measures, and the long-time effects on the construction industry will have a rather low impact). Among the most affected branches of the industry is the non-residential branch, with investors reducing the cash inflow due to uncertainties. The public investments maintained a mostly constant level, a fact that played a positive role in the industry.

\subsection{COVID-19 Effects}

As for the quantitative results, the first objective of the research was to identify the main effects that the COVID-19 disease and the pandemic stoppage regulations had upon the Romanian construction sector. To obtain a better relevant image of the industry, the items describing the effects of the COVID-19 pandemic crisis on the construction sector were built using the results of the qualitative interviews. Each item was measured on a 5-point Likert scale (with 1 representing the minimal value for being affected and 5 representing extremely affected).

Table 3 offers a summary of the responses in terms of the afferent statistical parameters: mode, median, and range. The results obtained in Table 3 were graphically transposed, as can be seen in Figure 4. The items from 1 to 14 correspond to the first Table 3 column, the potential COVID-19 effects. 
Table 3. Responses obtained for the section potential COVID-19 effects.

\begin{tabular}{|c|c|c|c|c|}
\hline Item & Potential COVID-19 Effects & Mode & Median & Range \\
\hline 1 & Projects stopped & 2 & 2 & 4 \\
\hline 2 & Projects delayed & 2 & 2 & 3 \\
\hline 3 & Projects canceled & 2 & 2 & 4 \\
\hline 4 & $\begin{array}{l}\text { Suffered delays due to } \\
\text { pandemic regulations }\end{array}$ & 2 & 2.5 & 3 \\
\hline 5 & $\begin{array}{l}\text { Planning and supply chain of the } \\
\text { projects suffered }\end{array}$ & 2 & 2 & 3 \\
\hline 6 & $\begin{array}{l}\text { Protection measures against COVID-19 spread } \\
\text { (disinfectants, information boards) led to high } \\
\text { costs inside the organization }\end{array}$ & 2 & 2 & 3 \\
\hline 7 & Labor impact and job losses & 2 & 2 & 3 \\
\hline 8 & $\begin{array}{l}\text { Cost overrun due to anti-COVID-19 spread } \\
\text { regulations taken by authorities }\end{array}$ & 3 & 2 & 3 \\
\hline 9 & Supply chain problems & 1 & 2 & 3 \\
\hline 10 & $\begin{array}{l}\text { Movement restrictions led to delays and } \\
\text { additional costs }\end{array}$ & 2 & 2 & 3 \\
\hline 11 & Investments have been delayed & 2 & 2 & 4 \\
\hline 12 & The organization's survival was in danger & 1 & 2 & 3 \\
\hline 13 & Competitiveness has become fiercer & 3 & 3 & 4 \\
\hline 14 & $\begin{array}{l}\text { The effects of COVID-19 led to boosting of the } \\
\text { construction market }\end{array}$ & 1 & 2.5 & 3 \\
\hline
\end{tabular}

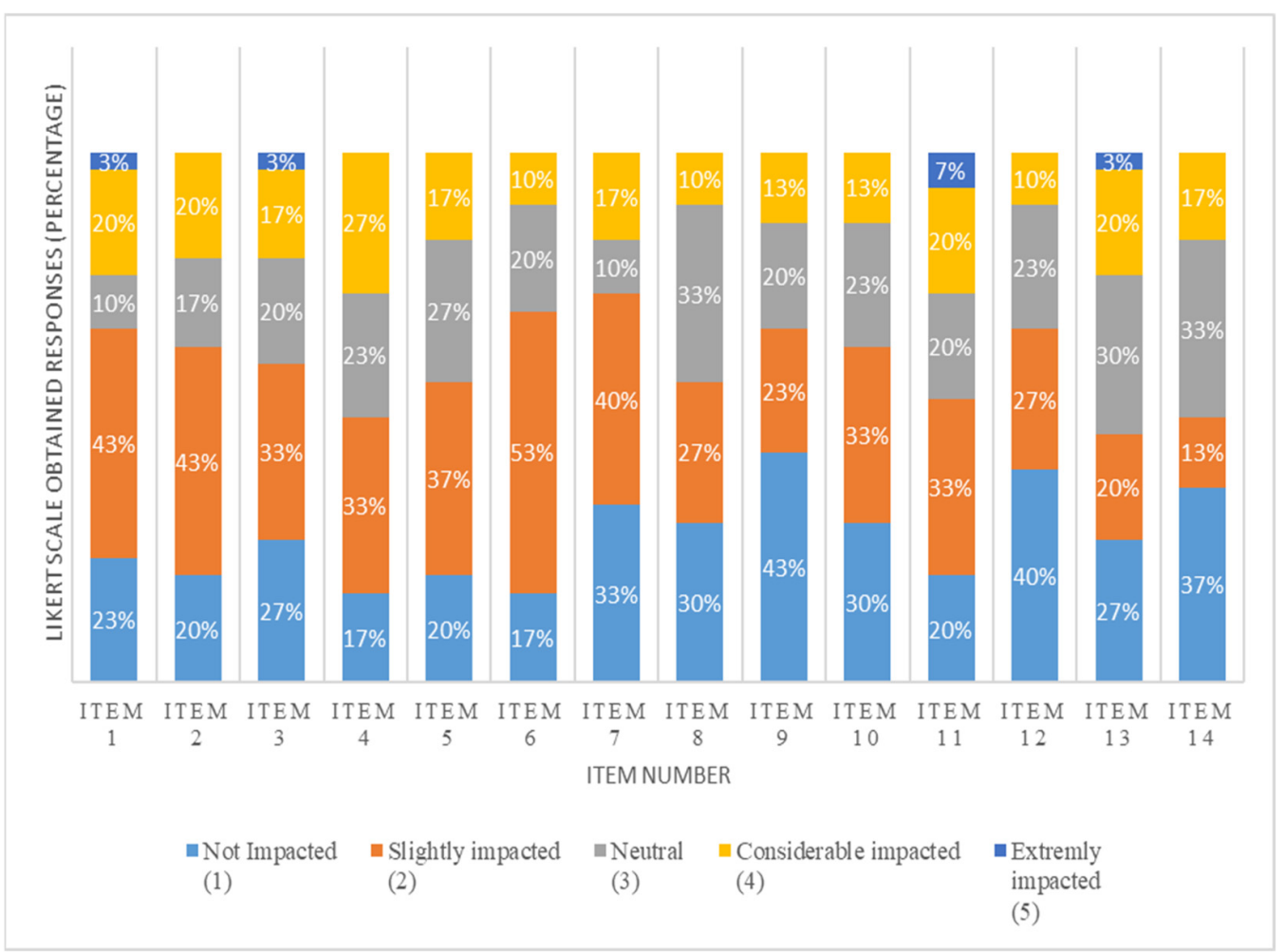

Figure 4. COVID-19 potential effects response obtained.

By analyzing the stopping, delaying, and canceling of the construction projects (items 1,2 , and 3), it can be noticed that all three categories have the same mode (2, the most frequent number in a data set) and median (2). They have different ranges, respectively, 3 and 4 , and one entry is registered in the extremely impacted category when talking about stopping and canceling the projects. Projects that were stopped (item 1) affected slightly $43 \%$ of the population, while about $20 \%$ of the population was considerably affected by 
the current pandemic situation. At the same time, more than $20 \%$ of the respondents agreed that no impact was noticed in matters of delaying, cancelling, and stopping of current works.

The industry suffered moderate delays (item 4 with median 2.5) because of the restrictive regulations against spreading of the COVID-19 disease, without extremely affected members. About $33 \%$ of the population was slightly impacted and suffered delays, while $26.7 \%$ reported that they had been considerably affected by the imposed measures. A number of five tries for absolutely no effects was counted, representing $17 \%$ of the total sample.

A concentration of the responses between slight and neutral impact in terms of affected planning and supply chain due to COVID-19 (item 5) can be noticed, with about $64 \%$ of the responses being concentrated in this interval. The value of the range underlines no extreme consequences due to this possible effect.

Slight impact of high-induced costs due to protection measures imposed at the construction sites and facilities (item 6) reflects $53 \%$ of the population. This item refers to increased costs due to the costs of information panels, disinfectants, masks, and so on.

A positive result was obtained when looking at the impact of the COVID-19 effects on labor and eventual job losses (item 7). Over $73 \%$ of the population situated itself between absolutely no effects and slightly affected. The mode and the median are both 2 , suggesting that no severe consequences up to this point are noticed. The Romanian construction sector presented a rather neutral position when it comes to cost overrun of the actual projects due to regulations imposed by the authorities for stopping the pandemic (item 8 ). The value 3 for the mode and the range indicates that no extremely impacted subjects were counted.

The problems at the supply chain level (item 9) seem to be rather sporadic, with more than $43 \%$ of the respondents reporting no negative effect at all, while $23 \%$ noticed slight consequences. With a median of 2 and a range of 3 , no extreme effects were noticed in the studied samples.

Movement restrictions that caused delays and additional costs (item 10) have been evaluated by $33 \%$ of the respondents as having a slight effect on the industry. As one can notice in Figure 4, the second number of entries represents the population reporting no effects at all. About $13 \%$ of the respondents answered that they had considerable additional costs and delays due to the movement restrictions, and half of the respondents were represented by middle-size and large to very large companies. This cause is likely to affect rather large companies that have a rich international portfolio.

When it comes to investment delays (item 11), a rather spread population can be noticed (range 4), and despite the fact that $33 \%$ of the respondents reported to be slightly affected, 20\% were registered in equal measures for the categories with zero, neutral, and considerable effects. The individuals reporting to endure considerable effects have their main work areas in the civil engineering and non-residential sector, part of the sector where public investment plays a major role. One may assume that a part of the population working with the public authorities suffered more in terms of future projects and investments. The population that reported not to suffer at all about future investments is constituted exclusively of construction teams, which was four of the six respondents working in the residential or rehabilitation sectors (focus). This item tends to tell us that the private sector seems to look further quite stable in terms of investments, while the public sector would rather be more careful.

Regarding the survival of the organization (item 12), the most entries had been noticed for the category who was not affected at all. The mode of 1 and median of 2 suggest that, during this difficult time period, a rather small number of organizations from the construction industry have encountered survival problems.

The item whether the competition became fiercer (item 13) is being characterized by the mode of 3 . Adding that the median also has the value 3 , a rather neutral position of the respondents is observed. About $26 \%$ of the respondents mentioned that competition does not become fiercer at all, and from this point of view, the structure of the construction market, in terms of competitiveness, remained rather constant. Although interestingly, 
almost all the respondents (five out of seven) who reported at least a considerable increase in terms of competition are active in the residential sector. This fact could suggest that, inside the residential sector, a plus in terms of competitiveness exists.

The last analyzed item regards an eventual boosting of the existent construction market (item 14) through a reduction in the work volume and disappearance of the so-called "ghost" or unreliable companies. The respondent's majority $(36.7 \%)$ reported not seeing a boosting of the market or suffering eventual consequences due to an increased dynamic inside the market. The second respondent group, with a weight of $33 \%$, has a rather neutral position regarding this item. Approximately $17 \%$ was observed for the category representing the considerably affected group, and once again, all the registered entities are active in the residential constructions sector. This may underline the above-mentioned aspect that the residential construction branch increased in terms of dynamics and competitiveness.

\subsection{Adoption and Efficiency of the Measures Taken for Stopping the COVID-19 Pandemic}

Two of the research objectives were related to identifying the most important countermeasures taken by the Romanian companies and analyzing their efficiency. A list of measures adopted by the companies in the construction sector was generated based on the literature review and the qualitative research. After that, the respondents were asked, based on a Likert scale from 1 to 5 , to rate the adoption degree of the imposed measures. In this scale, 1 means that the measures were not at all adopted, and 5 signifies that they were completely adopted. All these items measuring the adoption were generated by the responses of the expert invited to the in-depth interviews in the first step of the present research.

A summarization of the responses similar to the previous section was realized in Table 4. The obtained results were expressed as mode, median, and range. In Figure 5, a graphical interpretation of the responses obtained was performed for a better general overview. The items from 1 to 8 correspond to the first column from Table 4 (measures adopted).

Table 4. Responses obtained for the section adoption and efficiency of COVID-19 stopping measures.

\begin{tabular}{|c|c|c|c|c|}
\hline Item & Measures Adoption/Efficiency & Mode & Median & Range \\
\hline 1 & $\begin{array}{l}\text { Social distancing in offices and } \\
\text { construction sites }\end{array}$ & 3 & 3.5 & 4 \\
\hline 2 & Home office & 2 & 2.5 & 4 \\
\hline 3 & $\begin{array}{l}\text { Placing disinfectants, gloves, and masks in the } \\
\text { common spaces }\end{array}$ & 5 & 4 & 3 \\
\hline 4 & $\begin{array}{l}\text { Warning panels regarding maintaining } \\
\text { distance, wearing masks, or similar }\end{array}$ & 4 & 3 & 4 \\
\hline 5 & $\begin{array}{l}\text { Participants limiting/reduction of meetings } \\
\text { Switching real environment to virtual one }\end{array}$ & 3 & 3 & 4 \\
\hline 6 & $\begin{array}{l}\text { (Zoom meetings, } \\
\text { MS Teams) }\end{array}$ & 5 & 3.5 & 4 \\
\hline 7 & Splitting in working shifts to reduce contact & 1 & 2 & 4 \\
\hline 8 & $\begin{array}{l}\text { Efficiency of the adopted measures, did they } \\
\text { help for a better development of the works? }\end{array}$ & 4 & 4 & 4 \\
\hline
\end{tabular}

The social distancing measures, respecting the $1.5 \mathrm{~m}$ rule and similar distancing measures (item 1), have been well implemented along the construction sector. Observing the median with a value of 3.5 and a mode of 3 , the concentration of the responses lay between medium adoption and high adoption. The social distancing may be quite difficult for specific works at the construction sites, but apparently, the industry embraced it at a rather high level. 


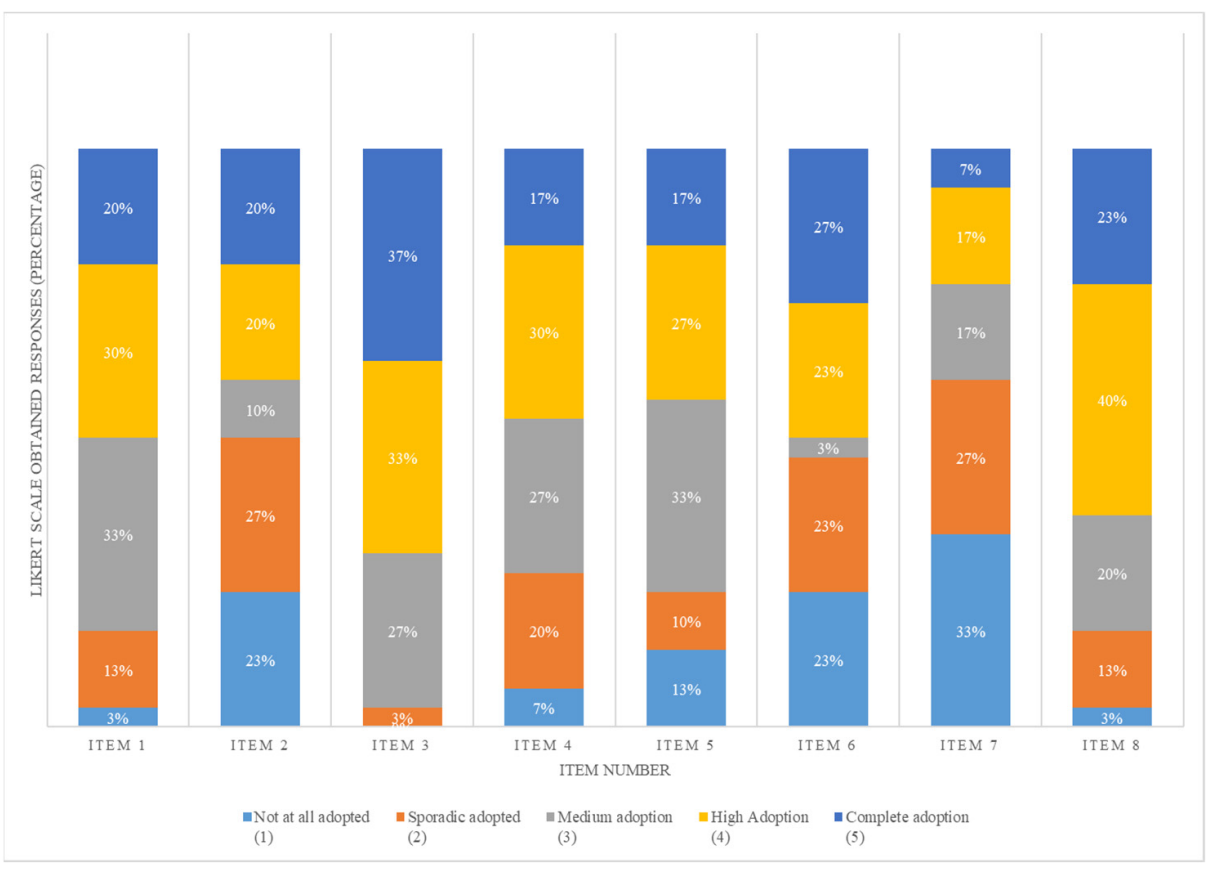

Figure 5. Adoption and efficiency of anti-COVID-19 measures response obtained.

Home office (item 2), on the other hand, had a rather sporadic adoption with the majority of the surveyed population $(26.7 \%)$ being followed by the non-adoption segment as well $(23.3 \%)$. Inside the population of individuals who have office jobs $(36.7 \%$ of total, Table 2), the implementation of this means avoiding the spreading of the pandemic embraced a rather spread pattern. The industry equipped the working places (offices or construction sites) with disinfectants, gloves, and masks at very high rates (item 3). Over $70 \%$ of the respondents reported that adoption of these measures was between high and maximum levels. Having a median of 4 and a mode of 4 , the wearing of masks along with the placing of the warning panels (item 4) also reached a high rate of adoption.

The optimization of the meetings, by reducing the number of people who attend them (item 5), had a medium adoption of about $33 \%$ of the respondents claiming this aspect. The second group representing $27 \%$ of the population reported high rates of limitation of the attendees.

A symmetrical distribution of the answers was obtained when analyzing the switching of the face-to-face meetings into online ones (item 6). Although the mode value is 5 for the complete adoption of these measures, this item has a median value of 3.5. The group of individuals reporting that such measures were not adopted at all consists exclusively of construction teams who work mostly on construction sites. One can notice that switching the "on site" meeting into an online environment is definitely not an easy task.

The splitting into working groups (item 7) was definitely a measure that had a poor implementation rate along the construction sector. Having the mode value 1 and the median 2, most individuals reported no adoption for such measures.

When talking about the efficiency of the measures taken for stopping the spreading of COVID-19 (item 8), the majority of the responses were concentrated around the high pole. Most of the participants (40\%) reported to consider the measures taken as efficient. It definitely helped the construction industry to overpass this critical point and to obtain good results under the given circumstances. The mode and the median, both with a value of 4 , emphasize once again the high performance of the measures embraced. 
4.5. Use of the Information Technologies and the Digitalization Level of the Romanian Construction Sector in the Pandemic Context

The last part of the online questionnaire consisted of five key questions concerning the usage of the information technologies and the current digitalization level of the Romanian construction sector. In addition, the role that digitalization plays in overcoming the current pandemic situation was determined. The respondents were asked to choose the digitalization level that best suits their company using a scale from 1 to 5 ( 1 being the lowest and 5 being the maximum).

The second question determined the level of knowledge existing inside the building industry regarding information technologies. The respondents were required to state which of the following sound familiar: 3D modeling, building information modeling (BIM), 3D printing, Internet of Things, augmented reality, lean management, drone and GPS systems, or cloud storing technologies. This issue had a multiple response choice.

With the help of a 5-point Likert scale having the option "is not the case", the actual degree of use of the various digital tools was analyzed. This topic includes four different categories, namely to what extent the following tools are being used inside the organization of the respondent: digital data, digital access, automation of the processes, and high connectivity.

The fourth item contains one open-ended question and asks the respondents to state which of the existing technologies are used inside their companies. The last enquiry uses a scale between 1 and 10, with 10 being the maximum value and 1 the lowest possible. The participants of the survey had to rate, using the above-mentioned scale, if a high digitalization level of the participant's organization would be an efficient manner of smoothly overcoming the present situation.

The current digitalization level of the Romanian construction sector looks rather positive (Table 5), with a mode of 3 and a median of 3.5. A remote number of two entries for the lowest and second lowest degree was registered. From the respondents of these categories, three of them work inside construction teams, and one is a general contractor. Two of them have mixed jobs, and the other two have field jobs.

Table 5. Current digitalization level responses.

\begin{tabular}{cccccc}
\hline Item/Scale & $\mathbf{1}$ & $\mathbf{2}$ & $\mathbf{3}$ & $\mathbf{4}$ & $\mathbf{5}$ \\
\hline $\begin{array}{c}\text { Rate the current digitalization level } \\
\text { of your organization (frequency) }\end{array}$ & 2 & 2 & 11 & 8 & 7 \\
\hline
\end{tabular}

From the participants rating their company as being maximum digitized, the majority (4) works in the design area, one is general contractor, and two are active inside construction teams. Five out of ten have office jobs, and two have a mixed profile of their jobs. When taking a deeper look at the respondent population working inside construction teams, it was noticed a range of 4 , depicting a quite diverse level of the digitalization. After analyzing the responses obtained from the design area, a range of 2 is obtained, with all the participants rating a level of at least 3 in terms of digitalization. It can be easily observed that a better digitalization level for the respondents having their activity field inside the design area exists. The digitalization of the "remote" construction sector has definitely not reached high levels, and there is enough room for upgrading.

The mean recorded in terms of rating the current digitalization level is 3.53 , and the standard deviation is 1.11753697-depicting an overall positive implementation and use of the digitalization techniques and technologies. The sample corresponds to a confidence interval of $3.533 \pm 0.3999$ or from 3.133 to 3.933 for a confidence level of $95 \%$. Although, at the general level, one shall consider the role of the respondent and the field where he/she is active. The contrast between individuals working in the design area and the ones active inside the construction teams (who carry physically the works) is quite high.

The level of knowledge of the Romanian construction sector regarding digital technologies presents itself as a solid one. As it can be seen in Figure 6, concepts such as 
3D modeling, building information modeling (BIM), or cloud technologies are relatively widespread and familiar to the building industry. Over $70 \%$ of the participants stated that they are familiar with 3D modeling, while $60 \%$ of those who responded found the term cloud, respectively, cloud-type data storage technologies, not foreign. This is gratifying, as the two converge in a common point as the degree of knowledge, and implementation will increase namely towards the building information modeling. Three-dimensional modeling is, in any case, a prerequisite to be able to move in a later step towards a transition to BIM.

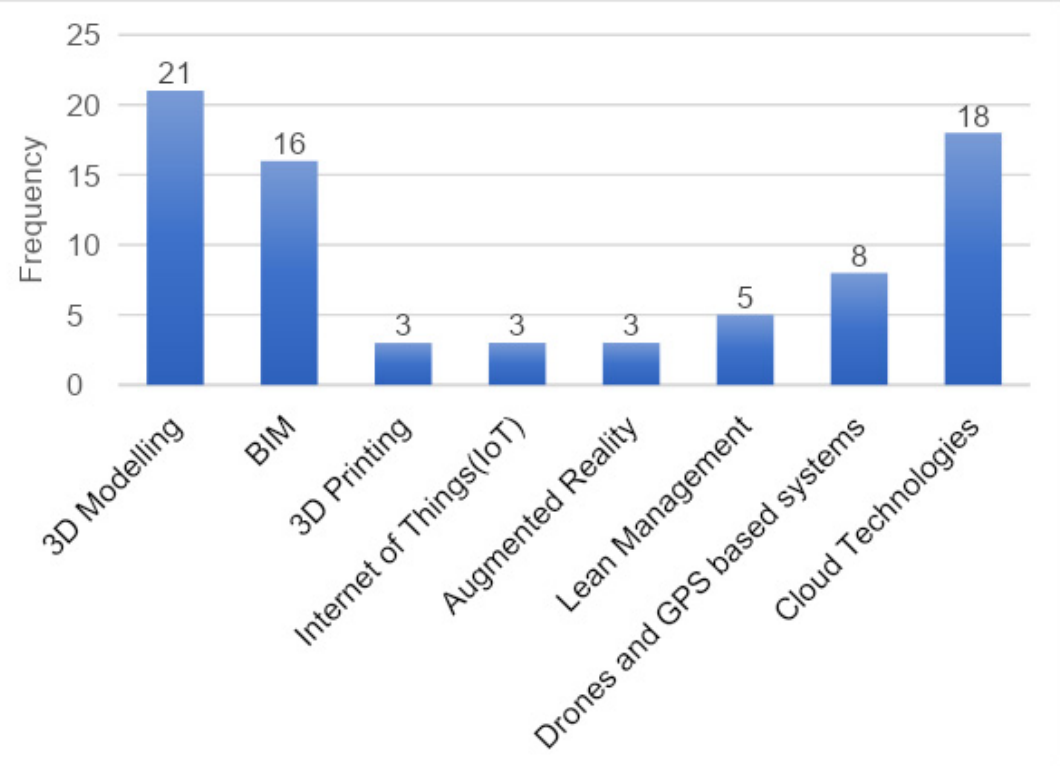

Figure 6. Responses to which of the following technologies sounds familiar.

BIM is familiar to over $50 \%$ of the respondent population. This fact is again a confirmation that such information technologies are starting to win notoriety in the Romanian construction sector as well. Technologies such as those mentioned above produce their advantages in the first phase in the construction design and engineering sector. BIM is, in the early stages, first implemented by companies from the design and architecture sector. In this case, 11 of the 14 companies performing services and works in the design and architecture works sector have confirmed that they know this technology.

A less gratifying perspective is that given by the construction companies, respectively, by those that play the role of general contractor or subcontractor, where out of 14 such entities, only 4 stated that BIM is a known concept. It is visible that the penetration of this technology is in its infancy for companies that have a portfolio of works on site.

A technology with a lower knowledge rate is the one that uses drones and positioning systems using GPS for measurements, location, and monitoring. This technology is familiar for about $25 \%$ of the total population. This digital tool is reported to be known mostly by companies that are active in the design and architecture branch, more specifically, to people who have over 10 years of experience in the field. Of those who responded, most have a mixed work profile (six out of eight), while two people have an office job.

The concept of lean management in the construction sector is known to $16 \%$ of the analyzed population. This type of technology is familiar to a wide range of people who carry out their activities either as a general contractor, in the design part, in construction companies, or in the architecture part, respectively to other categories. Information technologies such as 3D printing, augmented reality, or the Internet of Things reach a low degree of notoriety for the Romanian construction sector, with only $10 \%$ of the active population confirming to have heard of such techniques.

In the overall picture of the Romanian construction industry, technologies such as 3D modeling and those that use cloud technologies for data storage are well known. BIM has also become quite widespread in terms of the level of knowledge, while the rest of the tools 
and technological mechanisms that exist, such as drones, 3D printing, Internet of Things, or augmented reality, are still quite unfamiliar to the industry.

The third item from the digitalization section deals with the usage degree of the various digital tools inside the industry. Using a 1 to 5 Likert scale that includes a "not the case" possibility, responses were searched for the question "To what extent do you use the following digital means?". Four categories were selected for the analysis, as can be seen in Table 6.

Table 6. Usage degree of various digital tools.

\begin{tabular}{ccc}
\hline $\begin{array}{c}\text { Usage of the Digital } \\
\text { Means }\end{array}$ & Mode & Median \\
\hline $\begin{array}{c}\text { Digital data: electronic access to data and } \\
\text { digital communications }\end{array}$ & 3 & 3 \\
Digital access for project stakeholders using online \\
$\begin{array}{c}\text { organized platforms } \\
\text { Process automation: time management } \\
\text { systems, production, and time optimization } \\
\text { High connectivity with the help of different } \\
\text { apps, instant data transfer }\end{array}$ & 3.4 & 3 \\
\hline
\end{tabular}

The possibility of not applicable (0) was included, as it fully provided the participants to detail whether certain digital media have no place in the nature of the job that they carry or niche in which they work. For cases where the use of digital media does not exist or is not necessary, for a correct analysis, these values were excluded in the case of calculating the parameters as mode and median.

The first item concerns digital data, respectively, digital access to data in digital communications. The mode is 3, with $33 \%$ of the respondents evaluating this aspect as having an average use within the company in which they work. A percentage of $26 \%$ of the population answered that the use of digital data and the electronic access to data through digital communication reaches the maximum possible level. Those who have a maximum implementation are mostly (six out of eight) active in the design part (architects, designers, or engineers), while the rest of the population are general contractors.

Within the use of different organized platforms to facilitate the digital access of the participants of the different construction projects, three respondents evaluated that this modality does not belong to the character of the company or their job. One can observe a medium to high use of these digital means, the values of 3 and 4 within the Likert scale registering the same input frequency. About $13 \%$ of the total population analyzed evaluated this type of technology as reaching maximum levels, while $20 \%$ report a very low use of this digital medium. Of the $20 \%$, most are execution companies that operate either on site or in a mixed regime. The median value of 3 , and the most common value of 3 and 4, denotes an average upward use of these digital media.

The automation of the processes using time and production management systems received from the majority of the respondents $(30 \%)$ the value 3 . This is also the median and the mode for the whole data set, suggesting a medium usage of such technologies inside the Romanian construction sector. With a frequency of 4, the "not the case" option was the best suitable one for two design companies, one construction team, and one general contractor. For $16.7 \%$ of the participants, the maximum usage for different automation processes was registered. At the other pole, $20 \%$ of the respondents reported a very low usage of such techniques inside their organizations.

The last researched item inside the Likert scale is correlated to high connectivity by using different applications, respectively, instant data transfer. Representing over 33\% of the respondents, the majority of the individuals chose the maximum value as being the most appropriate. Most of the architecture and design companies (7 out of 10) reported reaching a maximum usage of connectivity digital tools. About $26 \%$ of the population reported a medium usage inside their companies of such techniques, and $13.3 \%$ is represented by 
the value of 4 . With a mode of 5 and a median of 3.5, a broad usage of this information technology has been reported. A quick data transfer and high connectivity are the premises that are necessary for obtaining proper results inside the construction industry.

The fourth analyzed item in the online survey contains an open-ended question addressed to the participants that focuses on the information technologies that are used inside the companies of the respondents. We chose the open-ended question to give the option to freely state which digital technologies exist and are being used inside the participant's organization. The online survey gave the possibility either to write as many characters as possible or to not complete this section.

Four individuals did not write anything at this question, while two individuals wrote that it is not the case. One entry stated that no information technology is being used inside his company. The most frequent responses obtained are 3D modeling, BIM, and Internet of Things, and all the responses can be observed in Figure 7. With a frequency of 13, 3D modeling is widespread in the use of Romania's construction industry. The second digital tool that is being used by the sector, is BIM, which recorded seven entries. The Internet of Things, cloud solutions, and different design tools recorded between two and three entries, suggesting that a rather scarce use of such techniques exists.

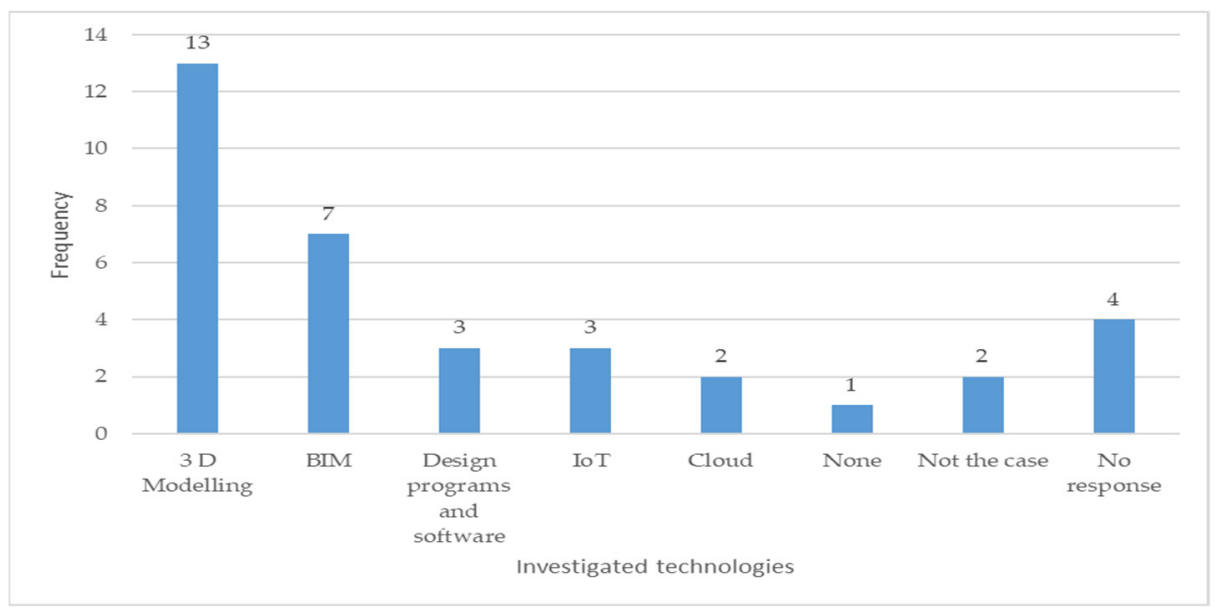

Figure 7. Responses obtained for the technologies used within the respondent's organization.

When summing up, the respondents, who stated that either is not the case or chose no response, reached a frequency of 6 . This represents about $20 \%$ of the population. It can be noticed that in the given pandemic context, 3D modeling along with BIM were the most embraced technologies by the Romanian construction industry. IoT, cloud, and design programs and software have also been used, but they reported a rather sporadic usage.

The last goal of this survey's subsection was to rate the statement that a high level of digitalization would be an efficient mean for overcoming the present pandemic situation more smoothly. The results can be seen in Table 7, where the most entries have been counted for the maximum value possible. The second number of entries, six, representing $20 \%$ of the respondents, agreed to rate with 8 the current item. About $50 \%$ of the total accounted responses were between the values of 8 and 10, suggesting that most of the population is positive when saying that a high level of digitalization could be a useful manner to pass the current situation. The majority of the individuals rating the current item with 10 are active in the design area. From the respondents, who rated the current item between 1 and 3 , four of them have the role of construction teams, two are general contractors (one individual is simultaneously having two roles), and one is active in the design area. All share having either mixed or field jobs. 
Table 7. Responses obtained for rating if a high digitalization level would help overcoming the current pandemic situation more efficiently.

\begin{tabular}{|c|c|c|c|c|c|c|c|c|c|c|}
\hline \multirow{2}{*}{ Item/Scale } & \multicolumn{10}{|c|}{ Frequency } \\
\hline & 1 & 2 & 3 & 4 & 5 & 6 & 7 & 8 & 9 & 10 \\
\hline $\begin{array}{c}\text { A high digitalization level of your } \\
\text { organization would be an efficient mean to } \\
\text { smoothly over stand the current situation } \\
\text { (average: } 6.47 \text { ) }\end{array}$ & 3 & 1 & 2 & 2 & 3 & 4 & 0 & 6 & 2 & 7 \\
\hline
\end{tabular}

One can notice that, although a strong segment of the construction industry is considering digitalization as a useful solution for overcoming such events, one smaller segment of the industry, mostly constituted of construction teams, does not rank digitalization as being useful in overcoming similar situations. It is perhaps the nature of the sector itself, which is characterized by some manual processes and methods who just cannot be digitalized [40], or it is the resistance to change $[40,41]$. The causes can be many; the purpose of this study is not to determine why a segment of the respondents does not consider digitalization a useful instrument, but to determine the objective position that the industry has regarding the current item. In general terms, the mean obtained for this item is 6.466667, the standard deviation is 2.98589276, and the median is 7, which are facts that suggest that the construction industry considers digitalization as a useful asset in overcoming similar unfortunate situations. For the computed values, there can be a $95 \%$ confidence that the population mean falls between 5.3981979 and 7.5351341, therefore, $\mathrm{a} \pm 1.0684681$ variation.

\section{Discussion}

The actual in-depth interviews and the quantitative survey aim to (1) identify the main effects of the COVID-19 pandemic on the Romanian construction sector, (2) identify the main countermeasures the industry has taken, (3) analyze the level of knowledge and the use of information technologies in the pandemic context, (4) assess the impact of the pandemic on the Romanian construction sector, and (5) evaluate the efficiency of the countermeasures.

The semi-structured interviews were conducted with six experts in the construction sector, and the results were used to develop the quantitative questionnaire [42]. The interviews with the experts provided insightful information in order to better understand the way they think and how they related to the pandemic challenges. According to the results, the anti-COVID-19 spreading regulations led to cost overruns (one of the experts naming up to 15-20\%). Similar findings have been found in the research of Gamil and Alhagar [11], who investigated the impact of the crisis on the survival of the industry. They also reported this item as one identified impact. The experts also reported delays in the projects, one of them reporting a five-week temporary stop at some of his construction sites. They concluded that investments are still being done at a rather smaller level compared to those at the beginning of 2020, and the most affected being the non-residential sector, where investors are somewhat uncertain of the actual pandemic situation.

Among the main countermeasures the industry has taken, the adoption of working from home was noticed. Among the biggest challenges directly connected to this item, the transformation of the processes from direct to online was agreed by the experts as being one of the main ones. Another notable challenge is the decrease in demand on the construction market for the first half of 2020.

Other measures and strategies against COVID-19 spreading, which the industry highly adopted and implemented, are social distancing inside offices and construction sites, placing of disinfectants, masks, and other similar materials in common spaces, placing warning panels, reducing the number of participants in direct meetings, and switching to online environment. Home office was between slightly and medium adopted among the Romanian construction sector because of the character of the industry, which is highly 
fragmented and concentrated around the construction sites. Working in different shifts had a very sporadic implementation. Among the measures and strategies adopted for stopping the spreading of the virus, the same measures as above-mentioned were found in the work of Bsisu [34], who investigated the impact of COVID-19 on the Jordanian construction industry, namely home office, social distancing, and safety regulations.

The experts confirmed that the features and nature of the construction sector allow up to a specific point to implement measures such as a home office and working in shifts due to the technological steps, which need to be done in a specific order without interruptions when working on construction sites. Bsisu reported in his study [34] the same items, stating that, in the case of field working, only $20 \%$ of the engineers believed that social distance is applicable in their work setting.

The findings in terms of evaluating the impact of the pandemic reveal that cost overrun of the projects and delays was one of the most frequent impacts. The interviews revealed that the experts consider digitalization as being among the most useful means to overcome this pandemic situation. The use of the existing technologies inside the Romanian construction industry has been intensified during the pandemic, and the interviews with the field experts offer valuable proofs in this matter. The digitalization and information technologies gained attention from the industry, and some of the processes converted from physical to digital.

One of the "benefits" reported in the interviews was the rapid development of the digitalization infrastructure of the public institutions. Besides, the intervention of the Romanian state needs to be mentioned, which helped the sector in overcoming this event by offering different facilities to the companies inside the industry, including tax reduction, technical unemployment, and similar.

The impact of the pandemic on the Romanian construction sector led to cost overrun of the ongoing projects because of assimilation of the social distancing measures, different delays generated by the pandemic conditions, and supply chain problems. Construction industry experts rated the majority of the measures implemented by the Romanian construction industry to stop the spread of COVID-19 as highly efficient.

As for the quantitative phase of the research, the online survey questionnaire was completed by a number of 30 individuals, with the majority of the respondent population being between 31 and 35 years old, highly qualified (master's degree), with a work experience of 5-10 years, and working in small companies in the design area.

Delays inside the industry because of the anti-COVID-19 regulations and the measures taken (such as lockdown) have been reported as having a slight to medium impact on the construction market. Gamil and Alhagar [11] report similar findings, although the intensity of the effects generated by the delays of the current projects had a higher value. At the same time, the industry was slightly impacted because of stopping or canceling the projects because of labor problems, movement restrictions, or reduced level of investment.

The main countermeasures taken inside the industry to avoid the spreading of the COVID-19 disease are the implementations of the safety and health regulations: placing of masks, gloves, disinfectants, and the switching of the direct (face to face) meetings to online ones. These two mentioned items reach very high values in terms of adoption.

The current digitalization level existing in the construction industry obtained a rating of 3.5 out of 5 , highly digitalized being the design area sub-sector. The "on field" construction teams report different levels of digitalization, with a very widespread spectrum. Some of the processes that take place on construction sites have a low potential of becoming digital because they require on-field contact and coordination. The experts shared the same feedback obtained from the surveys, highlighting that a rather decent level has been recently recorded, but in some sub-sectors, optimization and digitalization of some specific processes cannot so slightly occur. There is still room for digitalization, the construction sector being definitely somewhere at the bottom if compared with other industries [40].

The penetration of information technologies inside the Romanian construction sector presents a medium level, with technologies such as 3D modeling, BIM, and cloud data 
storing being quite known to the industry. More than $70 \%$ of the respondent population reported to have heard of 3D modeling, while over 50\% stated BIM and cloud techniques as being familiar. The digital tools that exist today inside this branch embrace a medium to a considerable degree of use during the given pandemic context. The majority of the respondents stated having a maximum use of the high connectivity through different applications and instant data transfer. A moderate use for digital data, i.e., digital communication, is present inside the industry. Digital access through online platforms and the automation of the processes have also been reported with a medium level of use. These categories are being used mostly by architecture and design companies active in the construction market, and at the other pole there are present companies that maintain their works mostly on the construction site (general contractors, subcontractors, and construction teams).

The feedback of the sector regarding which information technologies are being used in the present pandemic context reported that approximately $43 \%$ of the individuals use $3 \mathrm{D}$ modelling and over $23 \%$ use BIM on a constant basis. A quite remote usage of the IoT or cloud solutions has been observed. It can be noticed that, in terms of use, there is still enough room for improvement. However, one should consider the nature of the job of the respondent, with six individuals either not answering this item or stating that it is not the case to answer this inquiry.

Having a high digitalization degree was certainly a very useful way to overcome this novel pandemic situation. The survey has shown that over $50 \%$ of the respondents rated the above-mentioned statement between 8 and 10 (out of 10). The mean value obtained (6.47 out of 10) underlines the position of the industry, which considers digitalization as being a possible optimal solution in overcoming similar inconvenient events. The individuals that considered digitalization as not being so useful were mostly constituted out of construction teams.

The outcomes underlined that, among the effects with a medium impact, the cost overrun of the projects because of COVID-19-related stopping regulations can be counted. The respondents characterized the affirmation that competitiveness among the sector became fiercer as having a medium impact level. Regarding the competitiveness of the industry, Zamani et al. [8] also reported that, due to a shortage of existing projects, it has definitely increased. This fact could mean that the construction firms tried either to be more attractive for the demand segment inside the construction market, or the companies tried to obtain as many projects as possible due to the uncertainty level, leading to an increased competition level.

The efficiency of the adopted measures reached very high values, with the majority of the surveyed population rating this item 4 out of 5 . The respondents have been convinced that all the measures taken such as social distancing, working from home, switching of the physical environment to a virtual one, or placing the warning panels were good strategies for avoiding the virus propagation. The main results of the current research were compared with similar works reported, and the main conclusions can be visualized in Table 8 .

The findings of this study could help the "actors" of the construction industry when dealing with similar uncertain events in the future. Knowing the potential short-term effects and their impact can be of essential help when implementing the right strategy in similar pandemic contexts. In addition, discovering the importance of digitalization in dealing with such pandemic contexts could be a catalyst for digitizing the whole sector at a higher rate. Which information technology helped more or less and in what form was useful during the given circumstances are aspects that still need clarification, subsequent to this study.

Most of the results are confirmed by the strong evidence studies of Gamil and Alhagar [11], who interviewed 10 experts and received 129 online survey responses, and Salami et al. [18], who concluded on social distancing and its adoption within the construction sector, based on the results obtained by applying 101 questionnaires. At the same time, the role of digitalization in mitigating the COVID-19 effects is backed up by the study of Ogunnusi [7], who performed the research based on 71 survey responses. In addition, 
some results obtained in this study, such as the ones regarding the financial aid and the investment level, are also confirmed by weaker evidence studies of Zamani et al. [8] and King et al. [13]. A small deflection in results is obtained when comparing the current findings with the research performed by Bsisu [34], who studied, based on 150 online surveys, the Jordanian construction market, with different implementation levels of the home office being observed.

Table 8. Main findings of the current research compared with other prior works.

\begin{tabular}{|c|c|}
\hline Main Findings of the Current Research & Findings of Other Researchers \\
\hline $\begin{array}{c}\text { Delays of current projects because of anti-COVID spreading } \\
\text { regulations and of lockdown: Interviews (several delays) and } \\
\text { questionnaires (slight to medium impact) reported delays of } \\
\text { current projects. }\end{array}$ & $\begin{array}{l}\text { Gamil and Alhagar [11] suggest the industry is very impacted } \\
\text { from this effect. } \\
\text { King et al. [13] report also delays as being a significant problem. }\end{array}$ \\
\hline $\begin{array}{l}\text { Investment level rather low / reduced number of projects: The } \\
\text { interview results indicate that investments are conducted at a } \\
\text { rather lower level compared to } 2020 .\end{array}$ & $\begin{array}{l}\text { Zamani et al. [8] identify, in the majority of the interviews (for } \\
12 \text { of the } 20 \text { construction experts), a reduced number of projects. }\end{array}$ \\
\hline $\begin{array}{l}\text { Financial aid (government): The Romanian Government offered } \\
\text { tax reduction, technical unemployment, and other } \\
\text { similar measures. }\end{array}$ & $\begin{array}{c}\text { Zamani et al. [8] states that the government provided different } \\
\text { funding to help the entrepreneurs and the companies. } \\
\text { Ogunnusi et al. [7] mention the government's efforts in } \\
\text { this matter. }\end{array}$ \\
\hline $\begin{array}{c}\text { Competitiveness became fiercer: The impact on competitiveness } \\
\text { was assessed at a medium level. }\end{array}$ & Zamani et al. [8] state that competitiveness increased. \\
\hline $\begin{array}{l}\text { Impact of COVID-19 led to cost overruns: Experts mentioned in } \\
\text { interviews cost overruns of up to } 15-20 \% \text {. }\end{array}$ & $\begin{array}{l}\text { Gamil and Alhagar [11] reveal that the projects were very } \\
\text { impacted in this matter. } \\
\text { King et al. [13] report the same findings, although an exact } \\
\text { approximation of the extra costs is hard to be performed. }\end{array}$ \\
\hline $\begin{array}{l}\text { Survival of the organisation/uncertainty of survival: The } \\
\text { survival of the organizations was not affected. }\end{array}$ & $\begin{array}{c}\text { Gamil and Alhagar [11] report the industry having a neutral } \\
\text { position regarding this effect. }\end{array}$ \\
\hline $\begin{array}{c}\text { Home office: It was assessed as a slight to medium } \\
\text { implementation, being mostly adopted by design and } \\
\text { architecture companies (office jobs). }\end{array}$ & $\begin{array}{c}\text { Bsisu [34] indicates that most office-working engineers adopted } \\
\text { a "home office", with their productivity remaining at the } \\
\text { same level. }\end{array}$ \\
\hline $\begin{array}{l}\text { Social distancing: It was highly adopted within the Romanian } \\
\text { construction sector. }\end{array}$ & $\begin{array}{l}\text { Bsisu [34] states that social distancing was adopted, but the } \\
\text { results show that it is applicable for only } 20 \% \text { of the field jobs. } \\
\text { Salami et al. [18] report such measures as being adopted. }\end{array}$ \\
\hline $\begin{array}{l}\text { Role of digitalization: Digitalization is one of the most useful } \\
\text { ways to overcome the pandemic. }\end{array}$ & $\begin{array}{l}\text { Ogunnusi et al. [7] state that the situation enforced the } \\
\text { compulsory use of technology, i.e., the deployment of } \\
\text { technological tools. }\end{array}$ \\
\hline
\end{tabular}

\section{Conclusions}

The construction industry seems to be slightly affected by the current COVID-19 disease, showing a rather decent image with an investment level to a certain extent lower if compared to the first quarter of 2020. All the interviewed experts agreed that, before the pandemic crisis, the industry displayed a strong image with many investments and ongoing projects.

Among the main negative aspects generated by the COVID-19 pandemic, the lockdown, social distancing, and safety and health regulations, which came along to stop the spread of the virus, can be counted. The industry stated through its experts that increased costs were noticed because of the restrictions imposed when travelling (limited number of persons in car/accommodations) and because of the lockdown (one expert reported three major projects being stopped for about five weeks). The survey participants rated with sporadic (reduced) effects the problems related to the supply chain, the job losses and labor impact, the movement restrictions, and the delayed investments. Representatives of the industry have rated the statement that competition has become fiercer as having a medium impact.

Among the most important countermeasures adopted by the Romanian construction industry, the switching of the work from direct to online (home office), separation of the employees and maintaining just the minimum number of the employees in the offices, 
reducing the number of participants in meetings, and switching the real environment to the virtual one can be counted. The countermeasures with a high adoption for stopping the pandemic are the placing of disinfectants, gloves, and masks in the common spaces, social distancing, and switching of the real environment to the virtual one.

Some of the existing information technologies such as 3D modeling, BIM, or cloud storage technologies are quite familiar for the Romanian construction sector, while other digital tools such as 3D printing, augmented reality, or drones are less known to the industry. In terms of digital tools being used in the pandemic context, the researched items, including digital data and digital communications, digital access, and automation of the processes, embrace a medium level of use. The companies that are active in the design subsector have the above-mentioned techniques quite well in use. On the other hand, it can be noticed that the "on site" organizations suffer from a rather reduced level of use, with enough room for improvement existing at this moment inside the sector. In terms of high connectivity with the use of different applications and instant data transfer, a good level of use exists, with this tool enjoying a medium to high embracement.

The digital technologies mostly used by the Romanian construction industry are $3 \mathrm{D}$ modeling (over $43 \%$ of the respondents) and BIM (20\%). The use of the information technologies in the pandemic context reached high rates, and the field experts stated that digitalization through its entire means increased and that some of the processes turned digital. The pandemic changed the way in which the industry looked upon the existing digital technologies in a positive manner.

At the Romanian construction sector level, the impact of COVID-19 had only marginal effects in terms of stopped projects, canceled projects, or planning. The only considerable problems with medium impact encountered are the cost overrun caused by the adoption of the pandemic's anti-spread regulations and the delays generated by the pandemic regulations. Most of the measures that the Romanian construction industry implemented for stopping the spreading of COVID-19 were rated as being highly efficient by over $63 \%$ of the surveyed population.

The interviews revealed the position of the experts that consider digitalization to be among the most useful means to overcome this pandemic situation. The "benefit" of these crises found in the interviews was the rapid development of the digitalization infrastructure of the public institutions. In addition, the help of the Romanian government needs to be mentioned, supporting the sector in overcoming this crisis by offering different facilities to the companies activating in the industry: tax reduction, technical unemployment, and other similar measures.

The recent economic crisis and the COVID-19 pandemic increased the relevance of the economic resilience analyzed at regional, national, or European level, referring to the whole economy or only to a specific industry. As long as the probability of facing a new shock or crisis is very high, the companies and the government should be able to implement the necessary measures to increase the resilience capacity of the entities they are responsible for. In this respect, the study is relevant for the entrepreneurs acting in the building industry, offering some examples of good practice regarding the way the Romanian construction industry dealt with the pandemic effects, emphasizing the role of the digitalization in mitigating the negative impact of the sanitary crisis.

The long-term effects of the COVID-19 disease are yet to be discovered. It is a fact that the building sector has a specific "inertia", and the construction of actual projects being the result of what has been realized a couple of years before. Therefore, what will happen at a later time would be an interesting future research topic.

Author Contributions: Conceptualization, V.L., L.-G.M. and I.C.S.; methodology, V.L., L.-G.M. and I.C.S.; data collection and data analysis, V.L. and I.C.S.; writing-original draft preparation, V.L.; writing-review and editing, L.-G.M. and I.C.S.; supervision, L.-G.M. All authors have read and agreed to the published version of the manuscript. 
Funding: Authors are thankful to Romanian Ministry of Research, Innovation and Digitization, within Program 1-Development of the national R and D system, Subprogram 1.2-Institutional performance-RDI excellence financing projects, Grant no. 11PFE/30.12.2021, for financial support.

Institutional Review Board Statement: Not applicable.

Informed Consent Statement: Informed consent was obtained from all the subjects involved in the study.

Data Availability Statement: All the data presented in this article are available upon request from the corresponding author.

Conflicts of Interest: The authors declare no conflict of interest.

\section{References}

1. European Construction Industry Federation. Annual Report 2020; FIEC-European Construction Industry Federation: Brussels, Belgium, 2020. Available online: http://www.fiec.eu/en/library-619/annual-report-english.aspx (accessed on 2 February 2021).

2. Hui, D.S.; Azhar, E.; Madani, T.A.; Notumi, F.; Kock, R.; Dar, O.; Ippolito, G.; Mohugh, T.; Memish, Z.; Drosten, C.; et al. The continuing 2019-nCoV epidemic threat of novel coronaviruses to global health-The latest 2019 novel coronavirus outbreak in Wuhan, China. Int. J. Infect. Dis. 2019, 91, 264-266. Available online: https://www.ijidonline.com/article/S1201-9712(20)30011-4 / fulltext (accessed on 2 February 2021). [CrossRef] [PubMed]

3. World Health Organization. Naming the Coronavirus Disease (COVID-19) and the Virus That Causes It. 2020. Available online: https: / /www.who.int/emergencies/diseases/novel-coronavirus-2019/technical-guidance/naming-the-coronavirusdisease-(COVID-2019)-and-the-virus-that-causes-it (accessed on 2 February 2021).

4. IFO Institute, Leibniz Institute of Economic Research at the University of Munich. Press Release Construction Activity Expected to Fall by $7.8 \%$-Complete Recovery Not before 2023. 90th Euro Construct Conference. Available online: https:/ / euroconstruct. org/jart/prj3/wifo/data/uploads/euroconstruct/press/2020_90\%20-\%20EC\%20Press\%20Release\%20Munich.pdf (accessed on 2 February 2021).

5. European Commission, ECSO. Country Profile Romania. Available online: https:/ / ec.europa.eu/docsroom/documents/45386 (accessed on 5 February 2021).

6. National Institute for Statistics. The Resident Population at 1 January 2019, Losing 125,500 Persons. Press Release No. 212 from 2019. Available online: https://insse.ro/cms/sites/default/files/com_presa/com_pdf/poprez_ian2019r.pdf (accessed on 1 March 2021).

7. Ogunnusi, M.; Hamma-adama, M.; Salman, H.; Kouider, T. COVID-19 Pandemic: The effects and Prospects in the Construction Industry. Int. J. Real Estate Stud. Interest 2020, 14, 120-128.

8. Zamani, S.H.; Rahman, R.A.; Fauzi, M.A.; Yusof, L.M. Effect of COVID-19 on building construction projects: Impact and response mechanisms. IOP Conf. Ser. Earth Environ. Sci. 2021, 682, 012049. [CrossRef]

9. Ogunnusi, M.; Omotayo, T.; Hamma-Adama, M.; Awuzie, B.O.; Egbelakin, T. Lessons learned from the impact of COVID-19 on the global construction industry. J. Eng. Des. Technol. 2021, 20, 299-320. [CrossRef]

10. Jeon, J.; Padhye, S.; Bhattacharyya, A.; Cai, H.; Hastak, M. Impact of COVID-19 on the US Construction Industry as Revealed in the Purdue Index for Construction. J. Manag. Eng. 2022, 38, 04021082. [CrossRef]

11. Gamil, Y.; Allhagar, A. The impact of pandemic crisis on the survival of construction industry. A case of COVID-19. Mediterr. J. Soc. Sci. 2020, 11, 122-132. [CrossRef]

12. King, S.S.; Rahman, R.A.; Fauzi, M.A.; Haron, A.T. Critical analysis of pandemic impact on AEC organizations: The COVID-19 case. J. Eng. Des. Technol. 2021, 20, 358-383. [CrossRef]

13. King, S.S.; Rahman, R.A.; Fauzi, M.A.; Haron, A.T. Mechanisms for addressing the impact of COVID-19 on infrastructure projects. IOP Conf. Ser. Earth Environ. Sci. 2021, 682, 012047. [CrossRef]

14. Agyekum, K.; Kukah, A.S.; Amudjie, J. The impact of COVID-19 on the construction industry in Ghana: The case of some selected firms. J. Eng. Des. Technol. 2021, 20, 222-244. [CrossRef]

15. Al-Mhdawi, M.K.; Brito, M.P.; Abdul Nabi, M.; El-Adaway, I.H.; Onggo, B.S. Capturing the Impact of COVID-19 on Construction Projects in Developing Countries: A Case Study of Iraq. J. Manag. Eng. 2022, 38, 05021015. [CrossRef]

16. Amoah, C.; Bamfo-Agyei, E.; Simpeh, F. The COVID-19 pandemic: The woes of small construction firms in Ghana. Smart Sustain Built Environ. 2021; ahead-of-print. [CrossRef]

17. Aigbavboa, C.O.; Aghimien, D.O.; Thwala, W.D.; Ngozwana, M.N. Unprepared industry meet pandemic: COVID-19 and the South Africa construction industry. J. Eng. Des. Technol. 2021, 20, 183-200. [CrossRef]

18. Salami, B.A.; Ajayi, S.O.; Oyegoke, A.S. Coping with the COVID-19 pandemic: An exploration of the strategies adopted by construction firms. J. Eng. Des. Technol. 2021, 20, 159-182. [CrossRef]

19. Perrier, N.; Bled, A.; Bourgaoult, M.; Cousin, N.; Danjou, C.; Pellerin, R.; Roland, T. Construction 4.0: A survey of research trends. J. Inf. Technol. Constr. 2020, 25, 416-437. [CrossRef]

20. Forcael, E.; Ferrari, I.; Opazo-Vega, A.; Pulido-Arcas, J.A. Construction 4.0: A Literature Review. Sustainability 2020, $12,9755$. [CrossRef] 
21. Radulescu, C.V.; Ladaru, G.-R.; Burlacu, S.; Constantin, F.; Ioanas, C.; Petre, I.L. Impact of the COVID19 Pandemic on the Romanian Labor Market. Sustainability 2021, 13, 271. [CrossRef]

22. Dascalu, S. The Successes and Failures of the Initial COVID-19 Pandemic Response in Romania. Front. Public Health 2020, 8, 344. [CrossRef]

23. Siva, D.; Prasad, N.; Narayan, K.A. Strengths and Weakness of Online Surveys. IOSR J. Hum. Soc. Sci. (IOSR-JHSS) 2019, 24, 31-38. [CrossRef]

24. Rahi, S. Research Design and Methods: A Systematic Review of Research Paradigms, Sampling Issues and Instruments Development. Int. J. Econ. Manag. Sci. 2017, 6, 403. [CrossRef]

25. Hill, R. What sample is enough in internet survey research. Int. Comp. Technol. Electron. J. 21-st Century 1998, 6, 3-4.

26. Roscoe, J.T. Fundamental Research Statistics for the Behavioral Sciences, 2nd ed.; Holt Rinehart \&Winston: New York, NY, USA, 1975.

27. Bal, M.; Bryde, D.; Fearon, D.; Ochieng, E. Stakeholder Engagement: Achieving Sustainability in the Construction Sector. Sustainability 2013, 5, 695-710. [CrossRef]

28. Gamil, Y.; Rahman, I.A.; Nagapan, S.; Alemad, N. Qualitative approach on investigating failure factors of the Yemeni Mega Construction Projects. MATEC 2017, 103, 3002. [CrossRef]

29. Fielding, R.; Blank, G. The Sage Handbook of Online Research Methods; Vehovar, N., Manfreda, K.L., Eds.; Sage: London, UK, 2017; Chapter 9; pp. 149-150.

30. Chassan, J.B. Research Design in Clinical Psychology and Psychiatry, 1st ed.; Irvington Publishers Inc.: New York, NY, USA, 1979.

31. Shibani, A.; Hassan, D.; Shakir, N. The effects of pandemic on construction industry in the UK. Mediterr. J. Soc. Sci. 2020, 11, 6. [CrossRef]

32. Giesekam, J.; Barrett, J.R.; Taylor, P. Construction sector views on low carbon building materials. Build. Res. Inf. 2016, 44, 4 [CrossRef]

33. Bennett, R.; Härtel, C.J.; McColl-Kennedy, J.R. Experience as a moderator of involvement and satisfaction on brand loyalty in a business-to-business setting. Ind. Mark. Manag. 2005, 34, 1. [CrossRef]

34. Bsisu, K.A.D. The impact of COVID-19 Pandemic on Jordanian Civil Engineers and Construction Industry. Int. J. Eng. Res. Technol. 2020, 13, 828-830. [CrossRef]

35. Pathirana, L.P.D.S. Effect of COVID-19 and strategic response: A review of Sri Lankan Construction Industry. SSRG Int. J. Econ. Manag. Stud. 2020, 7, 73-77. [CrossRef]

36. Hanák, T.; Drozdová, A.; Marovi 'c, I. Bidding Strategy in Construction Public Procurement: A Contractor's Perspective. Buildings 2021, 11, 47. [CrossRef]

37. Lekan, A.; Clinton, A.; Fayomi, O.S.I. Lean Thinking and Industrial 4.0 Approach to Achieving Construction 4.0 for Industrialization and Technological Development. Buildings 2020, 10, 221. [CrossRef]

38. Nemoto, T.; Beglar, D. Developing Likert Scale Questionnaires. In Proceedings of the JALT Conference Proceedings, Kobe, Hyogo, Japan, 25-29 October 2013; JALT: Tokyo, Japan, 2013.

39. Smith, E.V., Jr.; Wakely, M.B.; DeKruif, R.E.; Swartz, C.W. Optimizing rating scales for self-efficiency (and other) research. Educ. Psychol. Meas. 2003, 63, 369-391. [CrossRef]

40. Dubas, S.; Paslawski, J. The concept of improving communication in BIM during transfer operation phase on the Polish market. Procedia Eng. 2017, 208, 14-19. [CrossRef]

41. Ullah, K.; Lill, I.; Witt, E. An overview of BIM Adoption in the Construction Industry: Benefits and Barriers. In Proceedings of the 10-th Nordic Conference on Construction Economics and Organization (CEDO), Tallinn, Estonia, 7-8 May 2019. [CrossRef]

42. Mathers, N.; Fox, J.N.; Hunn, A. Chapter 5: Using Interviews in a Research Project. Research Primary Approaches in Primary Care; Radcliffe Medical Press/Trent Focus for Research and Development in Primary Health Care: Sheffield, UK, 2002. 